\title{
Reaction Mechanism for the Replacement of Calcite by Dolomite and Siderite: Implications for Geochemistry, Microstructure and Porosity Evolution during Hydrothermal Mineralisation
}

\author{
Mark A. Pearce ${ }^{1}$, Nicholas E. Timms ${ }^{2}$, Robert M. Hough ${ }^{1}$, James S. Cleverley ${ }^{1}$ \\ ${ }^{1}$ CSIRO Earth Science and Resource Engineering, Australian Resources Research Centre, 26 Dick Perry \\ Avenue, Kensington, WA 6151, Australia \\ ${ }^{2}$ Department of Applied Geology, Curtin University, GPO Box U1987, Perth, WA 6845, Australia
}

\begin{abstract}
Carbonate reactions are common in mineral deposits due to $\mathrm{CO}_{2}$-rich mineralising fluids. This study presents the first in-depth, integrated analysis of microstructure and microchemistry of fluid-mediated carbonate reaction textures at hydrothermal conditions. In doing so, we describe the mechanisms by which carbonate phases replace one another, and the implications for the evolution of geochemistry, rock microstructures and porosity. The sample from the 1.95 Moz Junction gold deposit, Western Australia, contains calcite derived from carbonation of a metamorphic amphibole - plagioclase assemblage that has further altered to siderite and dolomite. The calcite is porous and contains iron-rich calcite blebs interpreted to have resulted from fluid mediated replacement of compositionally heterogeneous amphiboles. The siderite is polycrystalline but nucleates topotactically on the calcite. As a result, the boundaries between adjacent grains are low-angle boundaries $\left(<10^{\circ}\right)$, which are geometrically similar to those formed by crystal plastic deformation and recovery. Growth zoning within individual siderite grains shows that the low-angle boundaries are growth features and not due to deformation. Low-angle boundaries develop due to the propagation of defects at grain faces and zone boundaries and by impingement of grains that nucleated with small misorientations relative to each other during grain growth. The cores of siderite grains are aligned with the twin planes in the parent calcite crystal showing that the reactant Fe entered the crystal along the twin boundaries. Dolomite grains, many of which appear to infill space generated by the siderite replacement, also show alignment of cores along the calcite twin planes, suggesting that they did not grow into space but replaced the calcite. Where dolomite is seen directly replacing calcite, it nucleates on the Fe-rich calcite due to the increased compatibility of the Fe-bearing calcite lattice relative to the pure calcite. Both reactions are interpreted as fluid mediated replacement reactions which use the crystallography and elemental chemistry of the calcite. Experiments fluid mediated replacement reactions show that they proceed much faster than diffusion based reactions. This is important when considering the rates of reactions relative to fluid flow in mineralising systems.
\end{abstract}

\section{Introduction}

Reactions in carbonate-bearing rocks are ubiquitous from sedimentary dolomitisation of calcite (Machel 2004) through to high temperature metamorphism (e.g. Rathmell et al. 1999). As bulk rock chemistry or equilibrium P-T conditions change, carbonate minerals may replace each other and form multiple generations of carbonate within the same rock (Mumin and Fleet 1995). The addition of $\mathrm{CO}_{2}$-rich fluids along deformation zones (Wickham et al. 1994) leads to replacement of silicate and oxide minerals (e.g. Li et al. 2008) and the formation of carbonate veins. In this paper, we document the replacement of calcite by siderite and dolomite using detailed microstructural examination coupled to microchemistry, and explain this in terms of mineral replacement mechanisms.

The introduction of a fluid into a rock can have two major effects on the equilibrium mineral assemblage. Firstly, a fluid in disequilibrium with the rock changes the effective bulk composition and potentially the equilibrium assemblage (metasomatism). This can occur because the fluid is a reactant in the reaction as is the case in the transformation of granulites to eclogites (e.g. Austrheim 1987) or because of ionic components carried by the fluid (e.g. Beach 1974). For example introduction of K-bearing or $\mathrm{CO}_{2}$-rich fluids into mafic rocks can stabilise biotite and calcite at the expense of amphibole under the same PT conditions (White et al. 
2003). Secondly, fluids on grain boundaries and in pore networks provide fast diffusion pathways for the movement of reactants, short circuiting the need for volume or even 'dry' grain boundary diffusion. Under relatively low temperature conditions where diffusion is generally very slow, the reaction mechanism for the reequilibration of minerals with fluids is commonly seen to be fluid mediated solution-precipitation (Putnis and Putnis 2007).

Fluid mediated solution-precipitation reactions have been documented in numerous mineral systems in laboratory experiments and nature (Putnis 2009). These reactions produce a number of microstructural features that can be used to identify the reaction mechanism:

1) Replacement of existing grains: dissolution and precipitation occur at the same place resulting in the products pseudomorphing the reactant grains.

2) Sharp reaction interfaces: lattice diffusion is negligible so the interface between reactant and product is sharp

3) Porous products: continued reaction requires that porosity develops so that the reactant may reach the interface. For reactions where there is a decrease in the solid molar volume this readily occurs, but it has also been documented where the molar volume increases (Putnis et al. 2007).

4) Topotactic relationships: the reactions commonly use structural elements of the reactant, e.g. the $\mathrm{O}$ framework in replacement of leucite by analcime (Xia et al. 2009), so the reactant and product phases often have some crystallographic relationship. However, this is not exclusively the case (Zhao et al. 2009) and may be affected by other factors such as pH (Qian et al. 2011).

Of particular interest is the nature and development of carbonates during economic mineralization. Carbonate alteration is prevalent throughout many different types of mineral deposits due to the introduction of $\mathrm{CO}_{2}$-rich fluids during mineralisation events (e.g. Phillips and Brown 1987; Li et al. 2004; Djouka-Fonkwé et al. 2012). In this study, we focus on the replacement of calcite by siderite and dolomite in a sample from the Junction gold deposit in Western Australia (Polito et al. 2001). Microanalysis of the chemistry and crystallography of the replacement microstructures are used to assess the extent of solution-precipitation reaction mechanisms under ore-forming conditions.

\section{Geological Setting and Sample Description}

The sample studied is from the Achaean Junction gold deposit, Kambalda, Western Australia. Gold mineralization, with total reserves of $1.95 \mathrm{Moz}$ (Carver et al. 2004), is localised within the Junction dolerite, a differentiated iron-rich tholeiitic sill that intrudes the lower beds of the Black Flag group (Carey 1994). Fluid flow, which led to the formation of the Junction deposit, is hypothesised to relate to minor splays of the Boulder-Lefroy fault which lies $3 \mathrm{~km}$ to the west (Eisenlohr et al. 1989). Igneous differentiation has lead to the definition of 4 compositional zones (Carey 1994), of which zones 3 and 4 are enriched in iron relative to the bulk composition of the sill. These zones generally contain gold grades of $>2 \mathrm{~g} / \mathrm{t}$, and commonly $>20 \mathrm{~g} / \mathrm{t}$ in the most enriched parts of the deposit (Polito et al. 2001), present as free gold. The dolerite has been regionally metamorphosed to upper greenschist facies prior to the mineralisation event, and consists of the assemblage actinolite - hornblende - albite - chlorite - epidote - quartz (Witt 1993). Regional metamorphism is overprinted by a zoned metasomatic alteration halo. The assemblage of the innermost (biotite-calcite) zone is quartz-calcitealbite-biotite-chlorite-pyrrhotite suggesting alteration at $400^{\circ} \mathrm{C}$ (Witt et al. 1997), which is consistent with oxygen isotope thermometry from calcite and quartz veins, which shows a clustering of temperatures between $381^{\circ} \mathrm{C}$ and $434^{\circ} \mathrm{C}$ (Polito et al. 2001).

The sample, number 250 of Polito et al. (2001, see their fig. 3 for location), is from a diamond drill hole (subsequently excavated in the pit) and had a gold grade of $3.25 \mathrm{~g} / \mathrm{t}$ (Polito 1999). It was chosen for its microscopic visible gold content which is associated with key reactions such as the carbonate replacement documented in this study. Sample mineralogy consists of quartz-albite-biotite-chlorite-calcite-ilmenitepyrrhotite, with secondary chlorite and muscovite after biotite, siderite after calcite, and anatase after ilmenite. The abundance of biotite indicates that potassium metasomatism occurred early in the alteration history. The texture is heterogeneous on the thin section scale (Fig. 1), with areas of coarse grained (several millimetres long) 
biotite grain aggregates that have partially altered to muscovite and chlorite, and zones of finer grained intergrown biotite, chlorite, quartz and dolomite. At the edge of the coarse grained biotite are large (several millimetres long) calcite grains, which are the focus of this study. The quartz and carbonate are generally in equilibrium with respect to the oxygen isotopes (Polito 1999). Since there is visible gold in the quartz vein, it can reasonably be assumed that the quartz and calcite are syn-gold.

\section{Methods}

A polished section, $200 \mu \mathrm{m}$ thick, was prepared by polishing with progressively finer diamond paste (20 to 1 $\mu \mathrm{m})$, and then given a final polish with $0.06 \mu \mathrm{m}$ colloidal silica in sodium hydroxide $(\mathrm{pH}=9.8)$ for 4 hours using a Beuhler vibromet polisher. A thin coat $(\sim 5 \mathrm{~nm})$ of carbon was applied prior to SEM analysis, which was done using the Zeiss Ultra Plus field emission gun SEM at the Australian Resources Research Centre, Perth, Australia. Different datasets were acquired with different acquisition parameters depending on the spatial resolution and data types being collected (Table 1). The crystallography of the aggregates was mapped using electron back-scatter diffraction (EBSD) using a Bruker $\mathrm{e}^{-}$Flash detector and Bruker Esprit software. Energydispersive $\mathrm{x}$-ray (EDX) spectra were recorded concurrently with the EBSD patterns using a Bruker XFlash 5030 silicon drift EDX detector and were used in the phase discrimination of siderite and calcite. EBSD data were exported to Oxford Instruments' Channel 5 post-processing software, where the data were noise reduced by removal of isolated erroneous points (wild-spike correction), and zero solutions were assigned a phase and orientation using a nearest neighbour interpolation. During the extrapolation, the band contrast map was used to ensure that the data were not extrapolated across boundaries following the method outlined in Prior et al. (2009 section 26.2.4).

Simultaneous BSE imaging and EDX mapping was carried out at higher spatial resolutions with typical image resolutions of $1000 \times 750$ pixels resulting in pixel sizes of $100 \mathrm{~nm}$, which is on the order of $2-5 \%$ of the activation volume for $\mathrm{x}$-ray generation. False colour chemical maps were generated by assigning the intensity of the $\mathrm{Mg}, \mathrm{Fe}$, and $\mathrm{Ca} \mathrm{K \alpha}$-peaks from $\mathrm{EDX}$ spectra to red, green, and blue channels, respectively. BSE images were used to enhance the colour mixing to emphasise the different microstructural features using the algorithms within the Bruker Esprit 1.9 software. The resulting composite images benefit from combining the higher spatial resolution of the BSE image $(\sim 0.5 \mu \mathrm{m})$ with semi-quantitative chemistry from the EDX data. In addition to mapping, individual EDX measurements, carried out at a working distance of $6 \mathrm{~mm}$, at $20 \mathrm{keV}$ and $200 \mathrm{pA}$, were quantified using standards (dolomite for $\mathrm{Ca}$ and $\mathrm{Mg}$, pyrite for $\mathrm{Fe}$, and bustamite for $\mathrm{Mn}$ ). Carbon and oxygen were calculated based on stoichiometry.

Several factors needed to be considered for EBSD analysis of carbonate phases. Firstly, Calcite and Siderite both belong to the point group $\overline{3} \mathrm{~m}$ which includes two-fold rotations parallel to $<10 \overline{10}\rangle$, and therefore [0001] $=$ [0001]. However, the unit cell dimensions of calcite and siderite are sufficiently similar that reliable indexing based on the EBSD patterns is not possible. By quantifying the iron content of the EDX spectra the two carbonate phases are accurately discriminated during EBSD analysis. Secondly, due to ordering of $\mathrm{Ca}$ and $\mathrm{Mg}$ leading to rotation of $\mathrm{CO}_{3}{ }^{2-}$ molecules, dolomite (point group $\overline{3}$ ) does not have any two-fold rotation axes, so $[0001] \neq[0001]$. Misindexing was common using a dolomite match unit because pseudosymmetrically equivalent patterns are sufficiently similar and only differ by one or two, often weak, bands. Additional uncertainty is introduced because very high magnesium calcite and disordered dolomite (both $\overline{3} \mathrm{~m}$ ) have been found to precipitate from sulphide-rich fluids (Zhang et al. 2010). Detailed investigation of high resolution EBSD patterns reveals changes in lattice parameters due to band shifts between Mg-rich and Mg-poor carbonates but has failed to prove conclusively whether the Mg-rich phase is strictly dolomite or not. Therefore, both the Ca-rich and Mg-rich carbonates have all been mapped as 'magnesian calcite'. This approach still permits misorientations to be identified, but eliminates the systematic misindexing with $180^{\circ}$ misorientation around the a-axis. In this paper, we use the term 'grain boundary' to refer to a homophase boundary and 'phase boundary' to refer to a heterophase boundary.

EBSD data are represented in different ways using Oxford Instruments' Channel 5 software to highlight different aspects of the microstructure. 'Band contrast' is a measure of EBSD pattern quality, and is shown in 
maps to depict the general microstructure. Lighter pixels in band contrast maps represent better EBSD patterns whilst darker patterns represent higher defect concentrations (either dislocations or point defects) with the darkest pixels being grain and subgrain boundaries, and porosity. Misorientation maps show the minimum misorientation angle of each data point (pixel) relative to an arbitrarily chosen crystallographic orientation. The crystallographic orientation across grains may be uniform or vary smoothly (lattice bending) with sharper changes representing discrete boundaries (subgrain boundaries). Subgrain boundaries in misorientation maps are depicted explicitly and have been assigned colours by minimum misorientation angle. Pole figures were generated using the 'Mambo' module of Channel 5, and are plotted as lower hemisphere, equal area stereographic projections in the sample $x-y-z$ reference frame.

\section{Results}

In the following section, the spatial distribution of magnesium, calcium and iron within the carbonates, the crystallographic relationships between the different carbonates, and the distributions of crystallographic orientations within phases are documented.

\section{Inter- and intra-phase composition variations}

Chemical mapping of the carbonates shows the distribution of $\mathrm{Mg}$, Fe and $\mathrm{Ca}$ (Fig. 2a). Spot EDX analyses show that these three carbonates are compositionally dolomite (red), calcite (blue), and siderite (green). Dolomite is distributed in narrow linear zones with three orientations (5 -10 microns thick) resembling twins within the large calcite grain. Dolomite is also distributed more heterogeneously at the boundary between the carbonates and the mica grains, where dolomite is intergrown with calcite grains. Iron-rich carbonate (siderite) is present in the boundary between calcite and mica grains, and also occurs in the vicinity of several of the 'twins' in the calcite.

A montage of BSE images shows that all three phases are compositionally heterogeneous (Fig. 3). In this image, the greyscale of the siderite has been scaled separately from the calcite and dolomite to maximise the contrast in each phase. Calcite is extremely heterogeneous and contains irregular-shaped, micron-scale domains (lighter blebs in Fig. 3 and bright green 'Fe-Rich calcite' in Fig. 4) that are richer in magnesium and iron. These contain on the order of $15 \mathrm{~mol}_{\%} \mathrm{MgCO}_{3}$ and $12 \mathrm{~mol}_{\%} \mathrm{FeCO}_{3}$ compared to $1 \mathrm{~mol} \%$ and $2 \mathrm{~mol} \% \mathrm{MgCO}_{3}$ and $\mathrm{FeCO}_{3}$, respectively, for the calcite (see Table 2). Weaker variations in the Fe content of the calcite ('Fe-enriched calcite' in Fig. 4) are visible in the detailed EDX maps, and define broader irregular domains. The Fe-poor calcite domains are porous, especially along the boundaries with the Fe-enriched domains. Pores are generally sub-angular, less than $1 \mu \mathrm{m}$ across and do not appear to be interconnected.

The dolomite is also compositionally heterogeneous, showing concentric oscillatory zoning patterns that mimic the euhedral rhombohedral dolomite grains (Fig. 3 inset and Fig. 4b). Oscillatory zoning is present in dolomite grains located both in the calcite and along the twins (Fig. 4a). Remnant calcite can be identified in some of the thicker twins where the replacement by dolomite is not complete (indicated by ' $T$ ' on Fig. 2a). Where dolomitisation is more intense, the dolomite shows good rhombic shapes (Fig. 4b). In an intensely dolomitised domain parallel with a twin in the host calcite grain, the centres of the dolomite rhombs are aligned along the dominant twin direction (Fig. 3 - inset). The zoning pattern in the dolomite grains along the twins is asymmetric, indicating that dolomite grew inwards from the twin-host interfaces (Fig. 4b). Large (1-20 $\mu \mathrm{m}$ across) pores are associated with dolomitised domains. Many of the dolomite grains have extremely iron-rich $(10-12 \mathrm{~mol} \% \mathrm{Fe})$ cores and the oscillatory zoning is truncated against the surrounding calcite. Furthermore, the initial morphology of the early-formed dolomite mirrors the Fe-rich cores. Where dolomite does not form euhedral rhombs, the asymmetry of the zoning pattern indicates that the grains grew from the siderite-dolomite interface.

BSE images (Fig. 3 and enlargement in Fig. 5c) show that siderite grains contain oscillatory compositional zoning. EDX maps show that the dominant variation causing this zoning is substitution of $\mathrm{Ca}$ and $\mathrm{Mg}$ for $\mathrm{Fe}$ in the siderite. Manganese is also present at $<1 \mathrm{~mol} \%$ and shows small variations in chemical maps. The Mg-poor siderite (light grey in Fig. 5a) contains $6 \% \mathrm{MgCO}_{3}$ and $12 \% \mathrm{CaCO}_{3}$. In the more Mg-rich part (darker zone in Fig. 5a-c) the content of the other divalent cations rises to $\sim 11 \mathrm{~mol} \% \mathrm{Mg}$ and $15 \mathrm{~mol} \% \mathrm{Ca}$ (Table 2). Several 
distinctive compositional bands can be mapped between grains to define marker zones of a time sequence across different grains to show how the microstructure evolved with time (Fig. $5 \mathrm{c} \&$ e). One of these bands (the 'double band' of Mg-poor siderite corresponding to t1 in Fig. 5) is also highlighted in Fig. 3 (in red) to show the spatial distribution of the replacement across the entire siderite domain at that time. The oldest zoning shows the location of the grain cores. The cores of both the siderite and dolomite grains are commonly aligned with the traces of twin planes in the host calcite (Fig. 3 line A-A' and inset).

\section{Crystallographic Analysis}

Analysis of the crystallographic microstructure of the parent calcite grain is followed by examination of the other carbonate phases. A more detailed study of the siderite microstructures is then carried out to examine the substructure within the siderite polycrystals.

The large parent calcite grain is predominantly a single crystal orientation, and the mean orientation of the data indicates that the pole to (0001) plunges gently into the polished surface, close to sample ' $\mathrm{x}$ ' (Fig. 2b \& c). Pixels within $10^{\circ}$ of the mean orientation are coloured in shades of red in Fig. 2b, and show that the grain records a progressive, systematic misorientation across the mapped area. The three theoretical orientations of the e-twins were calculated; the e-twin misorientations are $78^{\circ}$ around $<2021>$ according to the disorientation convention (Valcke et al. 2006). Two of these orientations occur in the mapped area, and pixels within $10^{\circ}$ of these orientations are coloured in shades of green and turquoise, representing different e-twins. These domains align with the narrow, linear domains of dolomite and reduced band contrast (Fig. 2b). The pixels that are indexed as calcite but are misorientated more than $10^{\circ}$ from the parent or twin orientations are coloured blue (Fig. 2b). These orientations are limited to small sub-grains close to the calcite-mica interfaces or within dolomite-siderite altered domains. The large isolated region of calcite surrounded by siderite in the bottom right of the field of view of Fig. $2 \mathrm{~b}$ contains grains with orientations related to the both the parent calcite grains (coloured in shades of red) and the twin orientations (coloured in shades of green).

Dolomite grains are generally in the same orientation as the parent calcite grain (e.g., the domain in bottom right corner of Fig. 2b) or the dominant (green in Fig. 2b) twin orientation. Dolomite has replaced original twins in the calcite. Many of the thinner twins are replaced by dolomite of the same orientation as the parent calcite crystal and they are only visible due to chemical variations and not crystallographic ones (compare frequency of red Mg-rich twins in Fig. 2a. with green twin orientations in Fig. 2b). This is explained by examining the thicker twins (e.g. T in Fig. 2a) where replacement is not complete. Here the dolomite is growing in the parent calcite orientation and is consuming the twinned calcite from both sides thereby replacing twin orientation calcite with parent orientation dolomite. Along these twin boundaries the dolomite appears to be nucleating on the Fe-rich patches in the calcite just as in the rest of the grain (e.g. Fig. 4b).

The siderite occurs as polycrystals along the margin of the parent calcite single crystal (Fig. 2c \& d). Siderite grains have been coloured according to their crystallographic orientation relative to the calcite parent and 'twin' orientations (with the same $10^{\circ}$ misorientation tolerance as the calcite as in Fig. 2c). The pixels that are indexed as calcite but are misorientated more than $10^{\circ}$ from the parent or twin orientations are coloured yellow (Fig. 2c). This shows that most of the siderite grains are in orientations close to the mean orientation of the large calcite grain and a lower proportion are in orientations close to the two dominant twin sets in the calcite (Fig. 2c). However, $27 \%$ (by area) of the siderite grains are in orientations that have $>20^{\circ}$ misorientation with respect to the parent calcite grain or theoretical twin orientations. Since $98 \%$ of the mapped calcite orientation are within $20^{\circ}$ of these means, the nucleation of siderite grains with misorientations $>20^{\circ}$ are likely to have not been controlled by the calcite orientations.

Siderite grain shapes are dominantly controlled by $\{10 \overline{1} 4\}$ rhomb faces (r-planes). The orientations of the traces of the three rhomb faces of the parent calcite are shown in Fig. 2d. The stereogram shows the mean orientation (thin line) and the spread of orientations for each r-plane (shading). The coincidence of the traces of two of the three r-planes means that in the majority of the siderite grains, which are in the same orientations as the parent calcite grain, only two of the r-planes are visible. In other grains that are in different orientations, such as the grain labelled ' $M$ ' in Fig. 5b, all three r-planes are intersected by the thin section. 
To further investigate the growth of siderite as it replaced the calcite, the siderite grain orientations are plotted on Fig. 6, coloured by grain area. Most of the large grains are closer $\left(<5^{\circ}\right)$ to the orientation of the parent calcite phase than the smaller grains. A few of exceptions exist and these can be shown (using zoning patterns in) to have nucleated early during the replacement process because they contain older zoning patterns (Fig. 3). The spatial distribution can be seen qualitatively in Fig. $2 \mathrm{c}$ and Fig. $5 \mathrm{~b}$. There are numerous small grains surrounding the siderite that have greater misorientations (darker red colour) with respect to the parent calcite grains than the larger grains.

\section{Low-angle Boundaries}

Low-angle boundaries (with misorientation $<10^{\circ}$ ) are coloured according to misorientation angle from black $\left(1^{\circ}\right)$ through shades of blue $\left(2-10^{\circ}\right)$ to white $\left(\geq 10^{\circ}\right)$ (Fig. 2). There are very few low-angle boundaries in the calcite (Fig. 2b) although there is a gradual change in lattice orientation especially towards the mica grain at the left hand edge of the field of view. In the siderite, many of the boundaries identified in the pattern quality map are shown to be low-angle boundaries. These low-angle boundaries could either be crystal interface defects that propagated during grain growth, or be the result of crystal-plastic deformation. The origin of the low-angle boundaries can be investigated by using the chemical zoning in the siderite to track crystal growth.

Chemical zoning in the siderite can be seen in BSE imaging through atomic number contrast. This records the substitution of $\mathrm{Mg}$ and a limited amount of $\mathrm{Ca}$ and $\mathrm{Mn}$ for $\mathrm{Fe}$ in the siderite structure. The low-angle boundary microstructure in the same area is shown in a detailed (step size $100 \mathrm{~nm}$ ) EBSD map (Fig. 5a). The grains are defined by variations in $\mathrm{Mg}$ content and are generally euhedral. The grain facets are defined by the rhomb planes of the siderite (Fig. 5a inset stereogram).

Using the zoning to delineate growth, the low-angle boundaries can be divided into three groups dependent on their origin:

1) Impingement boundaries: boundaries between grains in similar but slightly misoriented orientations that have grown separately and now impinge upon one another;

2) Face defect-derived boundaries: boundaries that originate when a growing face hits a defect and splits into two different segments;

3) Zone axis defect boundaries: boundaries that originate from the intersection of the two faces so that a misorientation develops between two parts of the grain behind the two growing faces.

Impingement boundaries

An example of this type of boundary is shown in Fig. $5 \mathrm{c}$ and d. Boundary A is defined between two grains. Using the zoning in the grains as time markers (Ebers and Kopp 1979) the exterior geometry of the two grains can be tracked from through time (from t1 to t4). The geometry of boundary A was defined at or prior to $t 1$ in both grains. After t 3 , the grains came into contact. Because they are of similar orientations, their r-planes are in similar orientations and therefore the boundaries came together with only a slight mismatch (the boundary is not entire parallel to $\mathrm{t} 3$ ). The misorientation across boundary A is defined by the misorientation between the nuclei of the two grains. Since they both nucleated epitaxially on the same calcite crystal, there is only a few degrees of misorientation.

The grains could no longer grow perpendicular to A after impingement (there is no more calcite left to replace). At the time of impingement point $\mathrm{v}$ marked the corners of the two grains. The section of boundary to the right of $\mathrm{v}$ developed following impingement. Its geometry is not defined by any particular crystal face but rather by the relative growth rates of the two crystals. The grain underneath boundary A continued to grow with a planar crystal face parallel to the 4 time marker. In the other grain, the growth rate at the boundary highlighted varies along its length with time so that it changes geometry. At the end closest to boundary B, the growth is faster than close to boundary A. This is shown by the zoning being more diffuse close to boundary B. Boundary B is another example of a boundary where the geometry is caused by the relative growth rates of the grain either side of it whilst the misorientation across it is defined by misorientation of the initial nuclei. 
Face defect-derived boundaries

A face defect-derived boundary originates when a formerly uniform crystal face splits into two, most likely due to encountering a defect as it grows. An example of this is shown at point u (Fig. $5 \mathrm{c} \mathrm{\&} \mathrm{d)} \mathrm{where} \mathrm{the}$ misorientation is $<1^{\circ}$. As the boundary migrates (along the direction defined by the arrows) and the grain grows the misorientation increases. The locus of the increased misorientation is along the growth vector defined perpendicular to the boundary (black dashed arrow in Fig. 5d). A second example of this type of boundary is the boundary emanating from point $\mathrm{w}$ (Fig. $5 \mathrm{c} \& \mathrm{~d}$ ).

Zone axis defect boundaries

The boundaries are similar to those derived from face defects but originate from zone axes where two crystal faces intersect. The boundaries originating from point y (Fig. 5e \& f) are examples of these boundaries. Prior to point $y$ there is no misorientation in this area (although there is some variation in crystal orientation seen as variations in the shade of blue (in Fig. 5f). It is likely that the grain boundary here would be uniform and subvertical. A sub-horizontal segment grows as a result of the defect produced at $y$. As the two sub-vertical segments and the intervening sub-horizontal segment grow misorientation develops and is localised as boundaries that track the path of the zone axes.

\section{Discussion}

The microstructure developed in the carbonates from the Junction gold deposit document the replacement of calcite by siderite and dolomite. Following a proposal for the origin of the porous calcite, the discussion will focus on the replacement mechanism and the evolution from a single calcite crystal to its current polyphase state.

\section{Origin of Porous Calcite}

The microstructure of intergrown coarse-grained biotite and calcite, upon which the siderite and dolomite replacement is superimposed, is likely a replacement microstructure itself. The large biotite laths resemble amphibole grains due to their general shape, twinning and angular relationships to each other, which are similar to the $120^{\circ}$ amphibole cleavages (Fig. 1). Both actinolite and hornblende are present in the metamorphic assemblage of the Junction dolerite and are, in places, present as patchy intergrowths. Isochon plots show addition of K (Carey 1994) and, presumably, $\mathrm{CO}_{2}$ by metasomatism leading to breakdown of actinolite and the anorthite component of plagioclase to produce biotite and calcite (e.g. Witt 1991 reaction 6) by the following reaction:

$$
\begin{array}{r}
6 \mathrm{Ca}_{2}(\mathrm{Fe}, \mathrm{Mg})_{5} \mathrm{Si}_{8} \mathrm{O}_{22}(\mathrm{OH})_{2}+5 \mathrm{CaAl}_{2} \mathrm{Si}_{2} \mathrm{O}_{8}+17 \mathrm{CO}_{2}+10 \mathrm{~K}_{2} \mathrm{O}+4 \mathrm{H}_{2} \mathrm{O}= \\
10 \mathrm{~K}(\mathrm{Mg}, \mathrm{Fe})_{3} \mathrm{AlSi}_{3} \mathrm{O}_{10}(\mathrm{OH})_{2}+17 \mathrm{CaCO}_{3}+28 \mathrm{SiO}_{2}
\end{array}
$$

Variations in the iron content of the amphibole and spatial compositional heterogeneities caused by exsolution of multiple amphiboles could then have been inherited as the calcite completely replaced the amphibole. This would probably require rapid replacement to prevent diffusive re-equilibration of the Fe heterogeneities. If fluid mediated replacement reactions were responsible for this replacement phase then the process could be extremely rapid relative to lattice diffusion controlled processes. Labotka et al. (2004) show that length scales for replacement of albite by K-feldspar at $600^{\circ} \mathrm{C}$ are on the order of $25 \mu \mathrm{m}$ for a 6 day experiment compared to lattice diffusion distances of 125-225 nm. Fluid mediated replacement often forms porous products due to differences in solubility and change in molar volume of reaction, which would explain the micropores found in the calcite.

\section{Conceptual Model for Replacement}

1) Replacement is driven by an increase in the availability of $\mathrm{Fe}$ and $\mathrm{Mg}$ with which the calcite can react. This could be derived from breakdown of ferromagnesian minerals e.g. biotite and / or ilmenite or fluid sourced externally.

2) Siderite grains nucleated dominantly along twin boundaries, which served as fluid pathways into the calcite. They dominantly nucleated topotactically on the calcite resulting in a strong preferred 
orientation for the resulting polycrystal which has a spread of orientations similar to that of the original calcite.

3) Siderite grew by consuming the calcite adjacent to it with the addition of Fe from the intragranular fluid. The interface between the calcite and the siderite became increasingly porous due to the consolidation of the initial porosity in the calcite and the volume change of the reaction Calcite $\rightarrow$ Siderite.

4) Dolomite becomes the dominant replacement phase, replacing calcite along the twins by nucleating on Fe-rich calcite and filling some of the porosity created by the siderite.

\section{Source of Fe and $\mathrm{Mg}$}

Conversion of calcite to siderite and dolomite can be effected by the following reaction:

$3 \mathrm{CaCO}_{3}+\mathrm{Fe}^{2+}+\mathrm{Mg}^{2+}=\mathrm{FeCO}_{3}+\mathrm{MgCa}\left(\mathrm{CO}_{3}\right)_{2}+2 \mathrm{Ca}^{2+}$

Whole rock geochemistry from Junction (Carey 1994) and elsewhere in the southern Yilgarn (A. Bath, Unpublished data) show that on a deposit scale, Fe contents of mineralized mafic units are either unchanged from their protolith values or have been reduced by up to $20 \%$. Therefore, the source of the cations for carbonate alteration is likely to be locally derived and not metasomatic addition. Locally-sourced $\mathrm{Fe}$ is seen in a number of settings including Archaean greenstones in Canada (e.g. Kerrich and Fyfe 1981) and Carlin-style deposits (e.g. Cline et al. 2005)

Within the same thin section there is ilmenite breaking down to anatase, which releases iron. The biotite surrounding the carbonate is also breaking down to chlorite and muscovite. This reaction, balanced using the aluminium in the micas, also releases $\mathrm{Fe}$ and $\mathrm{Mg}$ :

$4 \mathrm{~K}_{2} \mathrm{Mg}_{2} \mathrm{Fe}_{3} \mathrm{Al}_{4} \mathrm{Si}_{5} \mathrm{O}_{26}(\mathrm{OH})_{4}+4 \mathrm{H}_{2} \mathrm{O}+5 \mathrm{CaCO}_{3}+10 \mathrm{CO}_{2}=2 \mathrm{~K}_{2} \mathrm{Al}_{6} \mathrm{Si}_{6} \mathrm{O}_{20}(\mathrm{OH})_{4}+\mathrm{Mg}_{3} \mathrm{Fe}_{7} \mathrm{Al}_{2} \mathrm{Si}_{6} \mathrm{Al}_{2} \mathrm{O}_{20}(\mathrm{OH})_{16}+$

$2 \mathrm{~K}_{2} \mathrm{O}+5 \mathrm{CaMg}\left(\mathrm{CO}_{3}\right)_{2}+5 \mathrm{FeCO}_{3}$

Image analysis performed on thresholded BSE images of the area mapped in Fig. 1 gives the area proportions of the different phases and, therefore, can be used to estimate the amount of $\mathrm{Fe}$ and $\mathrm{Mg}$ required to accomplish the reactions. The image is $30.7 \%$ siderite, which, assuming a $1 \mu \mathrm{m}$ thick section to convert area to volume, requires $1.14 \times 10^{-8} \mathrm{~mol}$ of iron to convert from calcite. The area of reacted ilmenite can provide approximately $4.5 \times 10^{-9}$ mols of Fe which is an order of magnitude too low to account for the total volume of the Fe carbonate observed. Assuming that the rest is from the biotite reaction, then this requires $6.9 \times 10^{-8}$ mols of biotite to react. This accounts for approximately $20 \%$ of the coarse biotite in the thin section (Fig. 1). It is difficult to evaluate the proportion of biotite reacted, as the products (chlorite and muscovite) are disseminated throughout the biotite grains because the reaction preferentially takes place along the biotite cleavage. However, there is sufficient biotite in the sample to provide all the $\mathrm{Fe}$ and $\mathrm{Mg}$ required, given these first order calculations. This reaction demands addition of both $\mathrm{H}_{2} \mathrm{O}$ and $\mathrm{CO}_{2}$. Fluid inclusion studies carried out on the quartz veins from Junction (including the vein part of this sample) show that the syn-gold veins have a range of inclusion types including $\mathrm{CO}_{2}$-rich, $\mathrm{H}_{2} \mathrm{O}-\mathrm{CO}_{2}$, and $\mathrm{H}_{2} \mathrm{O}-\mathrm{NaCl}$ (Polito et al. 2001). The presence of chlorine in the fluids would also assist in the mobility of cations.

\section{Nucleation}

A common feature of fluid mediated replacement reactions is that some aspect of the crystallography of the reactant is inherited in the product. This is a result of epitaxial nucleation of the product on the reactant and occurs because the product uses the common aspect of the crystal structure, e.g. the carbonate framework, as a template. Only small perturbations are required to transform the reactant into the product resulting in a lowering of the activation energy for nucleation (Xia et al. 2009). Following nucleation, the subsequent growth is controlled by the product which leads to the appearance that the crystallography is being maintained across a fluid filled interface. Many experimental studies of fluid mediated replacement are performed on single crystals and so are unable to investigate the detailed microstructure of polycrystalline samples (e.g. Putnis et al. 2007). However, the study of Xia et al (2009) showed that the product is a polycrystal with many $\mu$ m-sized crystallites replacing a twinned single crystal. Since all the crystallites nucleated from the same grain, the resulting 
polycrystal has a strong crystallographic preferred orientation (CPO) and a network of subgrains. Typically, this would be interpreted as deformation by dislocation creep and recovery, but the growth zoning in the siderite disproves that this is a deformation microstructure.

In this study, we have presented the first in depth study of fluid mediated reactions using coupled EBSD and EDX maps to investigate the detailed microstructure and microchemistry. This has shown that what appear as subgrains nucleate and grow from the twin boundaries (Fig. 3) and consume the intervening calcite. The regions furthest from the twins were consumed last and these are marked by the Mg-enriched siderite. The preference for twin boundaries arises because they are effectively grain boundaries (albeit extremely coherent ones with special orientation relationships), which provide access for the fluid and reactants to the calcite. This type of phenomenon has been documented in laboratory experiments along twin boundaries (Putnis et al. 2007), grain boundaries (Engvik et al. 2009) and fractures (e.g. Jamtveit et al. 2008; Janssen et al. 2010; Qian et al. 2010), which allow fluids access to fresh crystal surfaces. Not only do the boundaries allow the Fe and $\mathrm{Mg}$ to access the calcite, but the energy barrier for nucleation of new grains is not as large because they are boundaries and already have surface energy so nucleation is easier than within the crystal lattice. The presence of twin boundaries allowed fluid and reactants into the calcite grain, and so replacement did not proceed as a single front sweeping into the grain from the outside, but rather as multiple fronts that that advanced more or less simultaneously.

Not all the grains have nucleated in the same orientation as the calcite crystal or its twins. Some grains have grown in orientations that have little or no crystallographic relationship. This is in agreement with experimental studies that show that although topotactic relationships are a common feature of fluid mediated replacement reactions they are not ubiquitous (Qian et al. 2011). In these experimental studies, changes in conditions (e.g. $\mathrm{pH}$, temperature) have been shown to allow or prevent topotactic replacement. In the case of siderite replacing calcite, the grains which are not topotactic are mixed in with the grains that are, so it is unlikely that there is an external control. Grains nucleate by statistical fluctuations in the crystal lattice. The arrangement of atoms in the calcite makes it more likely that the atoms will be arranged in a siderite configuration, which is similarly oriented to the calcite, without major rearrangement. However, this does not prevent other orientations from forming successful nuclei. This ratio of topotactic to non-topotactic grains is therefore some function of the energy advantage gained by nucleating in a topotactic orientation.

Dolomite grains have nucleated around the Fe-rich calcite blebs that are present in the parent calcite grain. This is likely to have occurred for several reasons:

1) Substitution of smaller atoms, $\mathrm{Fe}$ and $\mathrm{Mg}$, into the calcite would cause strain along the interface between the Fe-rich and Fe-poor calcite. Therefore, by nucleating new dolomite, the free energy of the system is not only lowered due to a reduction in chemical energy but also by reducing the strain energy.

2) The presence of $\mathrm{Fe}$ and $\mathrm{Mg}$ allow the calcite lattice to contract, meaning that the lattice parameters are closer to that of dolomite than the unperturbed calcite. This type of phenomenon is similar to the mechanism observed in hydrothermal dolomitisation experiments where the first step in forming fully ordered, stoichiometric dolomite is to nucleate very high magnesian calcite (Sibley et al. 1994).

Dolomite also precipitated into the porosity created by the siderite-forming reaction. These grains nucleated and grew from the siderite-calcite interface because the mismatch between the dolomite and siderite unit cells is smaller than that between those of dolomite and calcite.

The cause of the switch from siderite growth to dolomite growth (along the calcite twins and into the porosity created by the sideritisation) is unknown. It may be due to a change in the pore fluid from a dominantly Febearing to Mg-bearing fluid. This is more likely if the fluid is externally sourced, and would result in the increase in magnesium seen in the siderite zoning (Fig. 5a). However, it is shown above that the Fe and $\mathrm{Mg}$ are likely to be sourced locally on the scale of the thin section. An alternative explanation is that the relative nucleation rates of siderite and dolomite are changed over time. One way this could occur is by an influx of sulphur in the mineralising fluid, which would facilitate sulphide growth. Hence, $\mathrm{Fe}$ is then taken up by pyrite 
and other Fe-rich sulphides, resulting in a dominantly Mg-bearing pore fluid. Furthermore, experimental evidence shows that aqueous sulphide can promote the nucleation and growth of dolomite by promoting dehydration of aqueous Mg complexes (Zhang et al. 2012).

The relative timing of dolomite growth relative to siderite is constrained by dolomite zoning microstructures (e.g., Fig. 3 - Inset) that shows that dolomite not only nucleates from the Fe-rich calcite but also from preexisting siderite grains. It is not possible to say unequivocally that all of the dolomite is post-siderite growth but it is consistent with the increase in $\mathrm{Mg}$-content of the siderite that dolomite growth should become more prevalent towards the end of the siderite replacement.

\section{Growth}

Growth competition between grains also inhibits the growth of nuclei that are not in 'favourable' orientations. This has been shown to be the case in crystal growth in veins (Nollet et al. 2005; Bons et al. 2012) where grains with fast growing faces adjacent to the vein out compete less favourably oriented grains. The 'halo' on the pole figure (Fig. 6) of smaller grains oriented further from the parent calcite orientation were prevented from growing by the faster growing, more favourably oriented grains. The spatial distribution of the small, unfavourably oriented grains versus larger more favourably oriented grain in Fig. $2 \mathrm{~d}$ and Fig. 5b supports this.

Orientation mapping of siderite grains reveals low-angle boundaries that have developed on crystal faces or at zone axes as the grains have grown. Similar features have been observed in calcite and dolomite using microtopography of cleavage planes using TEM (Paquette et al. 1999). These topographic steps displace the cleavage plane and cut straight across the zoning within the crystal.

\section{Porosity Evolution}

Calcite is initially porous (Fig. 7a), but the products, dolomite and siderite, do not contain intragranular porosity. Whilst it is possible to anneal the porosity generated through replacement reactions by subsequent surface energy-driven coarsening (Putnis et al. 2005), the preservation of porosity in the parent calcite is evidence against this occurring in these rocks. It is more likely that as the siderite grows, the porosity is consolidated into large pores along with the new porosity generated due to the decrease in the solid molar volume. Conceptually, it may be expected that the interface between the calcite being consumed and the dolomite being grown would become increasingly wide as porosity is added to it (as probably occurs initially, Fig. 7b). However, there is no evidence for this where the siderite-calcite interfaces are preserved. Instead, there are numerous large pores, some of which are now filled with dolomite. This suggests that there is diffusion of material on the scale of several siderite grain diameters (Fig. 7c), which allows the calcite-siderite interface to remain relatively tight and consolidates the porosity. The switch from individual grains with porous interfaces to larger pores is likely to occur as polycrystalline siderite regions form, as opposed to single siderite grains in a calcite matrix (Fig. 7b $-\mathrm{c})$.

The microstructures observed in the carbonates detail an evolution of porosity with the wall rocks at the Junction deposit. Initially, porosity is confined to twin boundaries and the intragranular porosity within the calcite grain. Whilst the intragranular porosity contributes significantly to the porosity, it is likely unconnected and therefore does not contribute to the permeability, which is dominated by the twin boundaries. As sideritisation occurs the intragranular porosity is reduced and consolidated as larger pores connected by grain and phase boundaries so permeability increases, allowing further fluid ingress. Subsequent dolomitisation occurs along the twin boundaries, at the siderite-calcite phase boundaries and in the open pore-space. Dolomitisation microstructures suggest that this reaction is also accompanied by volume loss promoting further reaction.

\section{Carbonate Replacement Reaction Mechanism(s)}

The criteria for dissolution-precipitation reactions outlined above are now critically evaluated with respect to the replacement of calcite by siderite and dolomite.

1) On the scale of the original calcite grains $(5 \mathrm{~mm})$, replacement is spatially coupled and the siderite and dolomite are pseudomorphing the original grain. 
2) The reaction interface between the products and the reactant calcite crystal is sharp. The interface is more complex than is often seen in simple single crystal experiments because the twin boundaries (Fig. 7a) allow ingress of fluids into the calcite crystal.

3) The product phases are less porous than the reactant calcite, which contains intragranular pores that would be expected in the product phase. However, porosity is created during the reaction and this is distributed as large pores (Fig. 7b-c). Moreover, the product phases are polycrystalline and therefore contain (sub-) grain boundary permeability to allow fluid to access the reaction interface. This porosity allows the coupling of dissolution and precipitation to be over a longer length scale than the grain boundary width usually observed in this type of reaction (Fig. 7c).

4) The reactions are topotactic so that the siderite and dolomite are largely in the same orientation as the reactant calcite grain. There are also grains which have nucleated in the orientations of the twins in the calcite grain. In addition to controlling the orientation of the nuclei, the calcite crystal also controls the rate at which the siderite grains grow (Fig. 6)

\section{Conclusions}

High resolution EBSD and chemical mapping have been used to show that siderite-calcite and dolomite-calcite replacement reactions from the Junction gold deposit occur by dissolution-precipitation coupled on the scale of the original calcite grains. Nucleation of new grains occurs along calcite twins as these allow fluid into the grain. The majority of grains nucleate topotactically on the original calcite, which results in a microstructure with a high proportion of low-angle grain boundaries. These are not deformation and recovery related but due to nucleation of adjacent grains in similar orientations. The major difference from other solution-precipitation reactions is that the reaction products are less porous than the reactants. Instead the porosity is consolidated into large pores some of which are later filled by dolomite. The cause of the change from siderite to dolomite as the replacement phase is uncertain but is likely to be due to addition of aqueous sulphide which decreases both Fe activity of the pore fluid by precipitating sulphide and decreasing nucleation energy for dolomite. Reequilibration by mediated replacement is much faster than diffusion controlled mechanisms. This example of replacement in natural carbonates is not only important for understanding the timescales of gold mineralisation, reconciling slow reactions with fast, catastrophic fracturing and fluid flow. 


\section{References}

Austrheim H (1987) Eclogitization of lower crustal granulites by fluid migration through shear zones. Earth and Planetary Science Letters 81: 221-232. doi:10.1016/0012-821X(87)90158-0

Beach A (1974) Amphibolitization of Scourian granulites. Scottish Journal of Geology 10: 35-43

Bons PD, Elburg MA, Gomez-Rivas E (2012) A review of the formation of tectonic veins and their microstructures. Journal of Structural Geology 43: 33-62. doi:10.1016/j.jsg.2012.07.005

Carey ML (1994) Petrography and geochemistry of selected sills from the Kambalda-Kalgoorlie region, WA. BSc (Hons) thesis, Australian National University, Canberra (unpubl.)

Carver RN, Brand NW, Mazzucchelli RH, Kelly GR (2004) Junction Gold Deposit, St Ives District, Western Australia. In: Butt CM, Cornelius M, Scott KM, Robertson IDM (eds) Regolith Expression of Australian Ore Systems. CRC LEME. Available at: http://crcleme.org.au/RegExpOre/Junction.pdf

Cline JS, Hofstra AH, Muntean JL, Tosdal RM, Hickey KA (2005) Carlin-type gold deposits in Nevada: Critical geologic characteristics and viable models. Economic Geology 100th anniversary volume 451-484

Djouka-Fonkwé ML, Kyser K, Clark AH, Urqueta E, Oates CJ, Ihlenfeld C (2012) Recognizing Propylitic Alteration Associated with Porphyry Cu-Mo Deposits in Lower Greenschist Facies Metamorphic Terrain of the Collahuasi District, Northern Chile-Implications of Petrographic and Carbon Isotope Relationships. Economic Geology 107: 1457-1478. doi:10.2113/econgeo.107.7.1457

Ebers ML, Kopp OC (1979) Cathodoluminescent microstratigraphy in gangue dolomite, the Mascot-Jefferson City District, Tennessee. Economic Geology 74: 908-918. doi:10.2113/gsecongeo.74.4.908

Eisenlohr BN, Groves D, Partington GA (1989) Crustal-scale shear zones and their significance to Archaean gold mineralization in Western Australia. Mineralium Deposita 24: 1-8

Engvik AK, Golla-Schindler U, Berndt J, Austrheim H, Putnis A (2009) Intragranular replacement of chlorapatite by hydroxy-fluor-apatite during metasomatism. Lithos 112: 236-246.

doi:10.1016/j.lithos.2009.02.005

Jamtveit B, Putnis CV, Malthe-Sørenssen A (2008) Reaction induced fracturing during replacement processes. Contrib Mineral Petrol 157: 127-133. doi:10.1007/s00410-008-0324-y

Janssen A, Putnis A, Geisler T, Putnis CV (2010) The experimental replacement of ilmenite by rutile in $\mathrm{HCl}$ solutions. Mineralogical Magazine 74: 633-644. doi:10.1180/minmag.2010.074.4.633

Kerrich R, Fyfe WS (1981) The gold - carbonate association: Source of CO2, and CO2 fixation reactions in Archaean lode deposits. Chemical Geology 33: 265-294. doi:10.1016/0009-2541(81)90104-2

Labotka TC, Cole DR, Fayek M, Riciputi LR, Stadermann FJ (2004) Coupled cation and oxygen-isotope exchange between alkali feldspar and aqueous chloride solution. American Mineralogist 89: 1822-1825

Li C, Ripley EM, Merino E, Maier WD (2004) Replacement of Base Metal Sulfides by Actinolite, Epidote, Calcite, and Magnetite in the Ug2 and Merensky Reef of the Bushveld Complex, South Africa. Economic Geology 99: 0173-0184. doi:10.2113/gsecongeo.99.1.0173

Li C, Ripley EM, Oberthür T, Miller JD, Joslin GD (2008) Textural, mineralogical and stable isotope studies of hydrothermal alteration in the main sulfide zone of the Great Dyke, Zimbabwe and the precious metals zone of the Sonju Lake Intrusion, Minnesota, USA. Mineralium Deposita 43: 97-110

Machel HG (2004) Concepts and models of dolomitization: a critical reappraisal. Geological Society, London, Special Publications 235: 7-63. doi:10.1144/GSL.SP.2004.235.01.02

Mumin AH, Fleet ME (1995) Evolution of gold mineralization in the Ashanti Gold Belt, Ghana: Evidence from carbonate compositions and parageneses. Mineralogy and Petrology 55: 265-280. doi:10.1007/BF01165121 
Nollet S, Urai JL, Bons PD, Hilgers C (2005) Numerical simulations of polycrystal growth in veins. Journal of Structural Geology 27: 217-230. doi:10.1016/j.jsg.2004.10.003

Paquette J, Vali H, Mountjoy E (1999) Novel TEM approaches to imaging of microstructures in carbonates: Clues to growth mechanisms in calcite and dolomite. Am. Miner. 84: 1939-1949

Phillips GN, Brown IJ (1987) Host rock and fluid control on carbonate assemblages in the Golden Mile Dolerite, Kalgoorlie gold deposit, Australia. Can Mineral 25: 265-273

Polito PA (Paul A (1999) Exploration implications predicted by the distribution of carbon-oxygen-hydrogen gases above and within the Junction gold deposit, Kambalda, Western Australia / Paul A. Polito. Thesis. Available at: http://digital.library.adelaide.edu.au/dspace/handle/2440/19421

Polito PA, Bone Y, Clarke JDA, Mernagh TP (2001) Compositional zoning of fluid inclusions in the Archaean Junction gold deposit, Western Australia: a process of fluid - wall rock interaction? Australian Journal of Earth Sciences 48: 833-855. doi:10.1046/j.1440-0952.2001.00903.x

Prior DJ, Mariani E, Wheeler J (2009) EBSD in the Earth Sciences: applications, common practice and challenges. In: Schwatz AJ, Kumar M, B. L A, Field DP (eds) Electron Backscatter Diffraction in Materials Science. Springer, New York

Putnis A (2009) Mineral Replacement Reactions. Reviews in Mineralogy and Geochemistry 70: 87-124. doi:10.2138/rmg.2009.70.3

Putnis A, Putnis CV (2007) The mechanism of re-equilibration of solids in the presence of a fluid phase. Journal of Solid State Chemistry 180: $1783-1786$

Putnis CV, Geisler T, Schmid-Beurmann P, Stephan T, Giampaolo C (2007) An experimental study of the replacement of leucite by analcime. American Mineralogist 92: 19-26. doi:10.2138/am.2007.2249

Putnis CV, Tsukamoto K, Nishimura Y (2005) Direct observations of pseudomorphism: compositional and textural evolution at a fluid-solid interface. American Mineralogist 90: 1909-1912

Qian G, Brugger J, Skinner WM, Chen G, Pring A (2010) An experimental study of the mechanism of the replacement of magnetite by pyrite up to 300 degrees C. GEOCHIMICA ET COSMOCHIMICA ACTA 74: 5610-5630. doi:10.1016/j.gca.2010.06.035

Qian G, Xia F, Brugger J et al. (2011) Replacement of Pyrrhotite by Pyrite and Marcasite Under Hydrothermal Conditions up to $220^{\circ} \mathrm{C}$ : An Experimental Study of Reaction Textures and Mechanisms. American Mineralogist 96: 1878-1893. doi:10.2138/am.2011.3691

Rathmell MA, Streepey MM, Essene EJ, van der Pluijm BA (1999) Comparison of garnet-biotite, calcitegraphite, and calcite-dolomite thermometry in the Grenville Orogen; Ontario, Canada. Contributions to mineralogy and petrology 134: 217-231

Sibley D, Nordeng S, Borkowski M (1994) Dolomitization Kinetics in Hydrothermal Bombs and Natural Settings. J. Sediment. Res. Sect. A-Sediment. Petrol. Process. 64: 630-637

Valcke SLA, Pennock GM, Drury MR, De Bresser JHP (2006) Electron backscattered diffraction as a tool to quantify subgrains in deformed calcite. Journal of Microscopy 224: 264-276. doi:10.1111/j.13652818.2006.01698.x

White RW, Powell R, Phillips GN (2003) A mineral equilibria study of the hydrothermal alteration in mafic greenschist facies rocks at Kalgoorlie, Western Australia. Journal of Metamorphic Geology 21: 455-468. doi:10.1046/j.1525-1314.2003.00454.x

Wickham SM, Janardhan AS, Stern RJ (1994) Regional Carbonate Alteration of the Crust by Mantle-Derived Magmatic Fluids, Tamil Nadu, South India. Journal of Geology 102: 379-398. doi:10.1086/629681 
Witt WK (1991) Regional metamorphic controls on alteration associated with gold mineralization in the Eastern Goldfields province, Western Australia: Implications for the timing and origin of Archean lode-gold deposits. Geology 19: 982-985. doi:10.1130/0091-7613(1991)019<0982:RMCOAA >2.3.CO;2

Witt WK (1993) Gold deposits of the Kalgoorlie-Kambalda-St. Ives areas, Western Australia : part 3 of a systematic study of the gold mines of the Menzies-Kambalda region. Geological Survey of Western Australia, East Perth, Western Australia

Witt WK, Knight JT, Mikucki EJ (1997) A Synmetamorphic Lateral Fluid Flow Model for Gold Mineralization in the Archean Southern Kalgoorlie and Norseman Terranes, Western Australia. Economic Geology 92: 407437. doi:10.2113/gsecongeo.92.4.407

Xia F, Brugger J, Ngothai Y, O’Neill B, Chen G, Pring A (2009) Three-Dimensional Ordered Arrays of Zeolite Nanocrystals with Uniform Size and Orientation by a Pseudomorphic Coupled Dissolution-Reprecipitation Replacement Route. Crystal Growth \& Design 9: 4902-4906. doi:10.1021/cg900691a

Zhang F, Xu H, Konishi H, Kemp JM, Roden EE, Shen Z (2012) Dissolved sulfide-catalyzed precipitation of disordered dolomite: Implications for the formation mechanism of sedimentary dolomite. Geochimica et Cosmochimica Acta 97: 148-165. doi:10.1016/j.gca.2012.09.008

Zhang F, Xu H, Konishi H, Roden EE (2010) A relationship between d104 value and composition in the calcitedisordered dolomite solid-solution series. American Mineralogist 95: 1650-1656. doi:10.2138/am.2010.3414

Zhao J, Brugger J, Grundler PV, Xia F, Chen G, Pring A (2009) Mechanism and kinetics of a mineral transformation under hydrothermal conditions: Calaverite to metallic gold. American Mineralogist 94: 15411555. doi:10.2138/am.2009.3252 


\section{Figure Captions}

Fig. 1: Plane polarised transmitted light image of the thin section used in this study. The slide was prepared as a fluid inclusion wafer so the section is $200 \mu \mathrm{m}$ thick. The carbonate grains that are the focus of this study are in the wall rock adjacent to a quartz vein. The wall rock is texturally heterogeneous with an area of large twinned biotite grains and another area of fine grained biotite and chlorite. Both areas have carbonate infilling between the phyllosilicates. The position of Fig. 2 is indicated by the white box.

Fig. 2: Microchemistry and microstructural relationships of calcite, dolomite, and siderite (step size $1.5 \mu \mathrm{m}$ ). a) EDX map showing magnesium (red - dolomite), iron (green - siderite) and calcium (blue - calcite) content of the carbonates. Also shown are the position of figures 4 and 5. ' $\mathrm{T}$ ' indicates incomplete replacement of calcite twins by dolomite. The carbonates are bounded by mica grains (brown due to presence of Fe and $\mathrm{Mg}$ ). $\mathrm{b}$ )

Misorientation image showing the orientation of calcite relative to the mean orientation of the parent grain (red) and the theoretical twin orientations (green, turquoise). Calcite pixels $>10^{\circ}$ from these orientations are coloured blue. Also shown are subgrain boundaries which are coloured from black through blue to white with increasing misorientation from 1 to 10 degrees. For further details see text. c) Misorientation image showing the misorientation of siderite pixels relative to the same three 3 orientations used in $b$. Remaining siderite pixels are coloured yellow. Also shown are subgrain boundaries coloured as for calcite. D) EBSD pole figures showing orientations of calcite and siderite coloured as in $b$ and c. Pole figures are lower hemisphere equal area projections showing c-axes (0001), a-poles $\{11 \overline{2} 0\}$, and r-poles $\{10 \overline{14}\}$. Also shown is a summary stereogram showing the range of orientations (shown in grey) that the traces of the r-planes could take in the section based on the spread of orientation within the large calcite grain.

Fig. 3: Large-scale BSE montage with the 'double band' defined by two Fe-enriched zones close together mapped out. This is interpreted as a time mark and shows the extent of replacement at this time. Lines A-A', BB' and C-C' show twin planes in the calcite which are sites of nucleation for both the siderite and the dolomite (inset).

Fig. 4: Detailed relationships between calcite and dolomite phases. a) Enhanced EDX map combining Mg (red), $\mathrm{Fe}$ (green) and $\mathrm{Ca}$ (blue) overlain on a BSE image showing calcite (blue) twins being replaced by dolomite (red). The calcite is heterogeneous in composition with lighter Fe-rich patches and more subtle Fe-enriched areas. Note zoning in dolomite which appears to nucleate on Fe-rich calcite. b) Enhanced EDX map with the same colour scheme as (a) showing dolomite replacing calcite. Dolomite grains show growth zoning picked out by $\mathrm{Fe}$ variations in the dolomite rhombs. Calcite is heterogeneous with Fe-rich patches. Note Fe-rich cores to a number of dolomite rhombs.

Fig. 5: Chemical zoning and EBSD data showing zoning and low angle distortion in siderite. a) BSE image of siderite grains surrounding a dolomite grains. Contrast is adjusted to focus on siderite zoning. B) EBSD map showing orientation variations in siderite. Pixels are coloured relative to two points denoted by 'p'. Other pixels are shown according to their pattern quality. Also shown are grain boundaries coloured according to their misorientation. C) Enlargement of BSE image with EBSD boundaries overlain. Blues denote boundaries between $2^{\circ}$ and $10^{\circ}$ and green $>10^{\circ}$. Distinct bands are highlighted as time markers $(\mathrm{t} 1-\mathrm{t} 4)$ in different grains. D) Enlargement of EBSD data coloured according to orientation relative to point ' $p$ '. E) Enlargement of BSE image with boundaries and the same time markers as in (c). F) Enlargement of EBSD data for the same area as in (e) with orientation coloured as in (b).

Fig. 6: Pole figures of siderite subgrains coloured by grain size.

Fig. 7: Microstructural evolution of the carbonate replacement reactions. A) Siderite grains (yellow) nucleate along the calcite twin plane (blue). B) Siderite grows and the porosity created by the reaction is consolidated along with the initial porosity (white circles) into increasingly large pores. C) As siderite replacement becomes more complete, porosity is consolidated into large pores. Further growth of siderite at the expense of calcite is accomplished by diffusion of material along phase boundaries to porous regions. D) Dolomite (red) grows in the large pore space and begins replacing calcite. Dolomite nucleates either on the siderite grains or the Fe-rich patches in the calcite (yellow blebs in blue calcite). 


\section{Calcite}

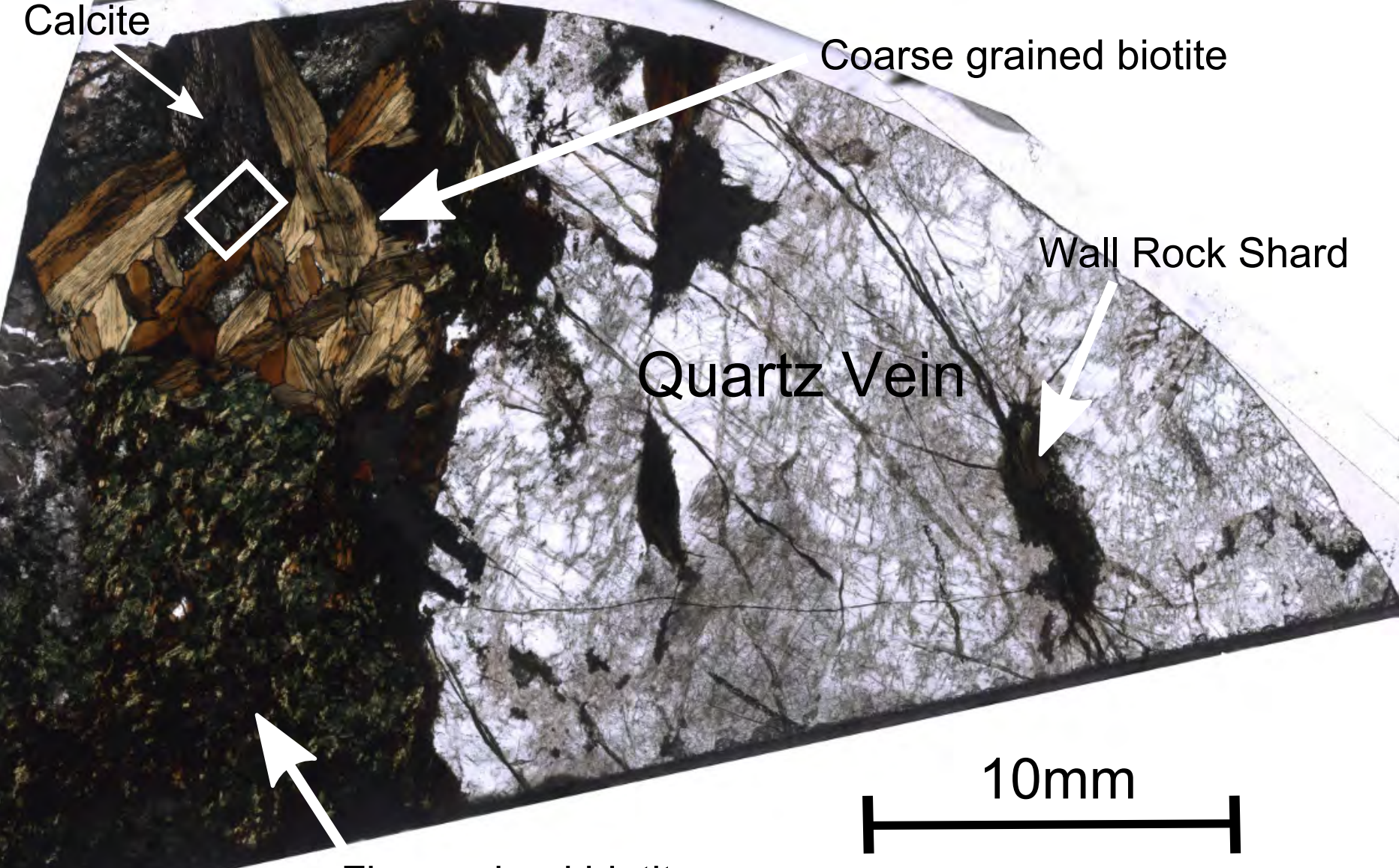

Fine grained biotite and chlorite

\section{$10 \mathrm{~mm}$}




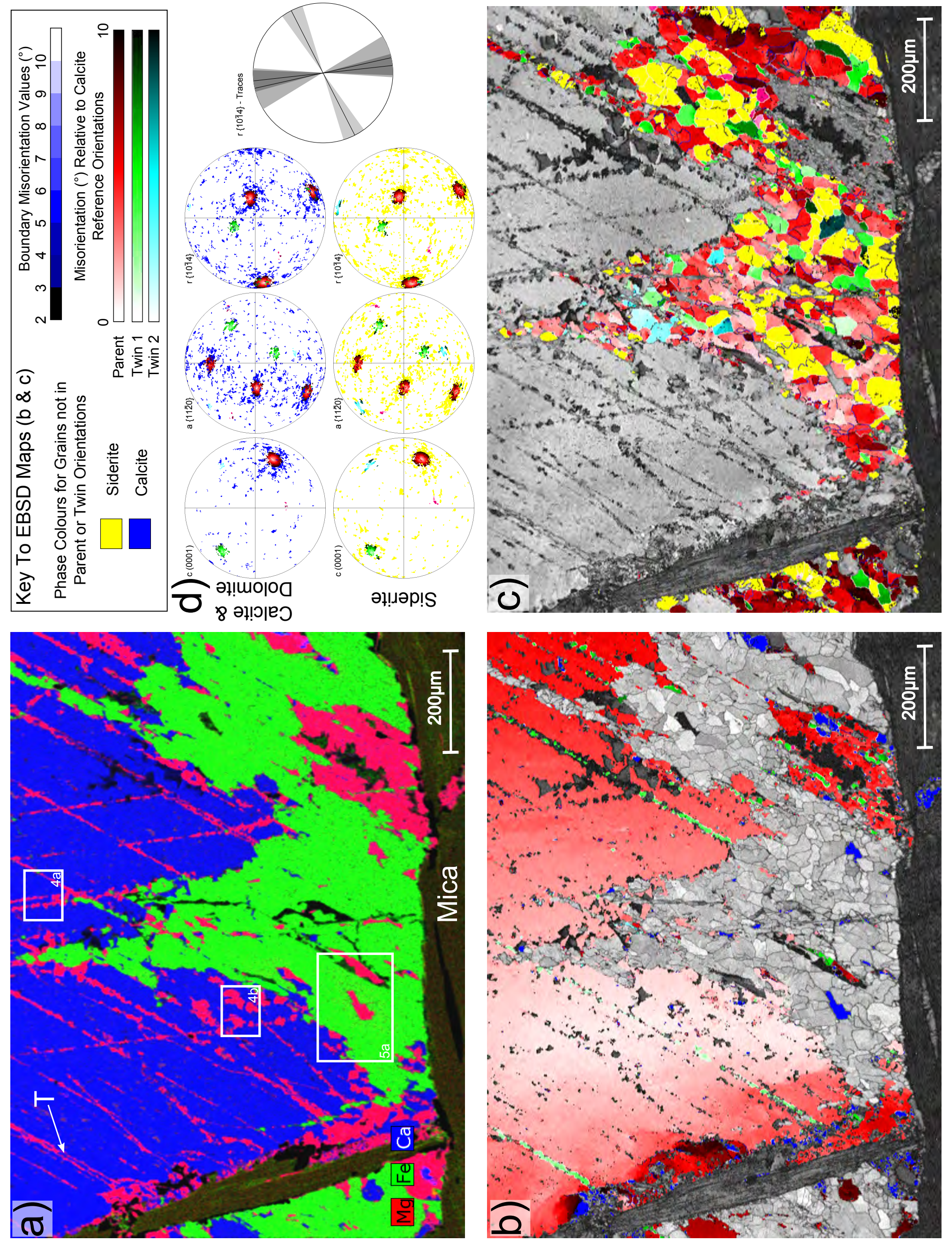




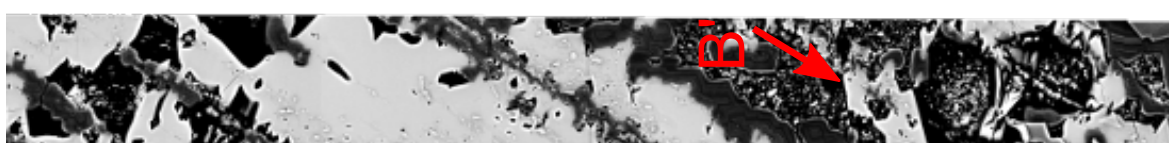

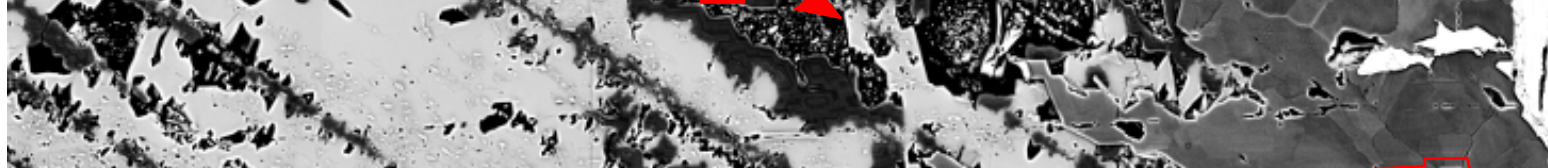

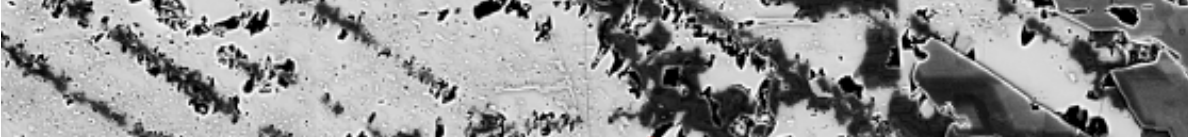

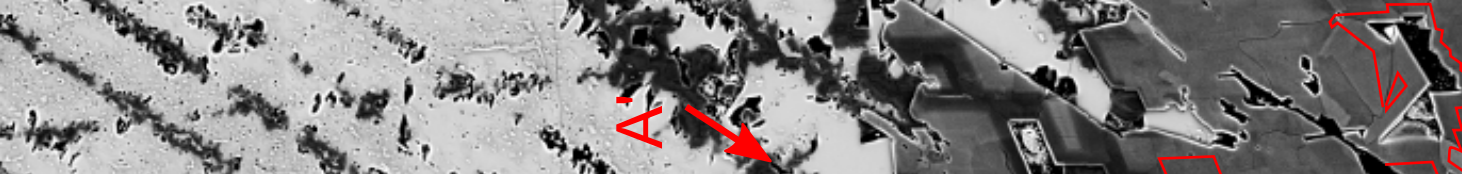

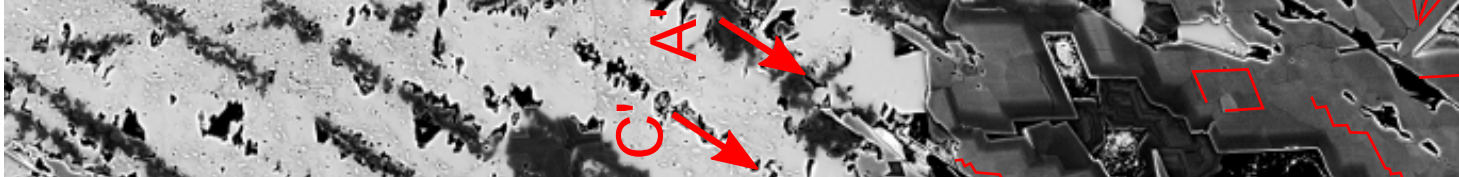

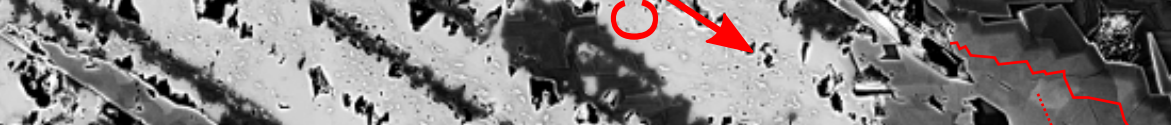

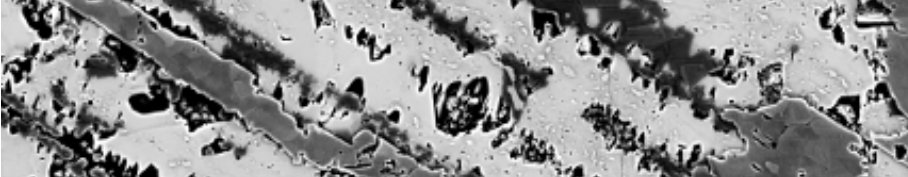
4\%

ses:

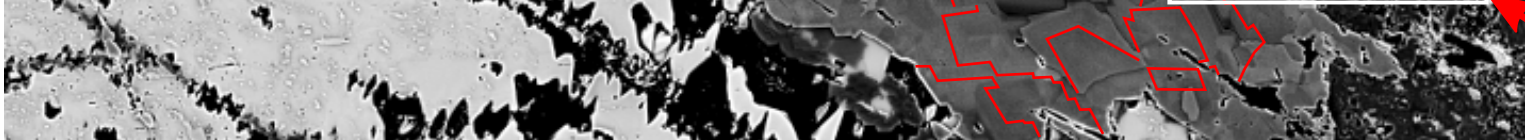

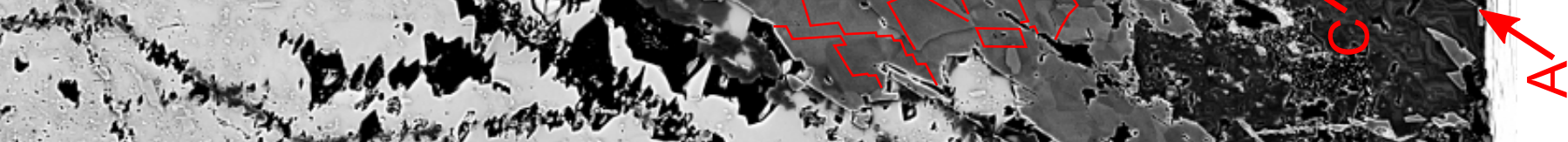

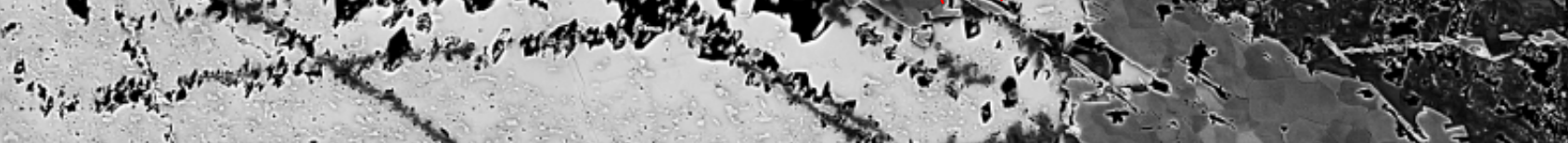
3

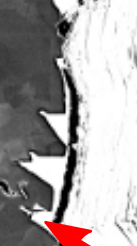

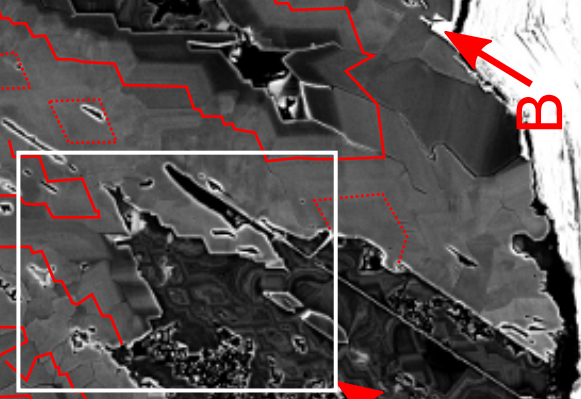

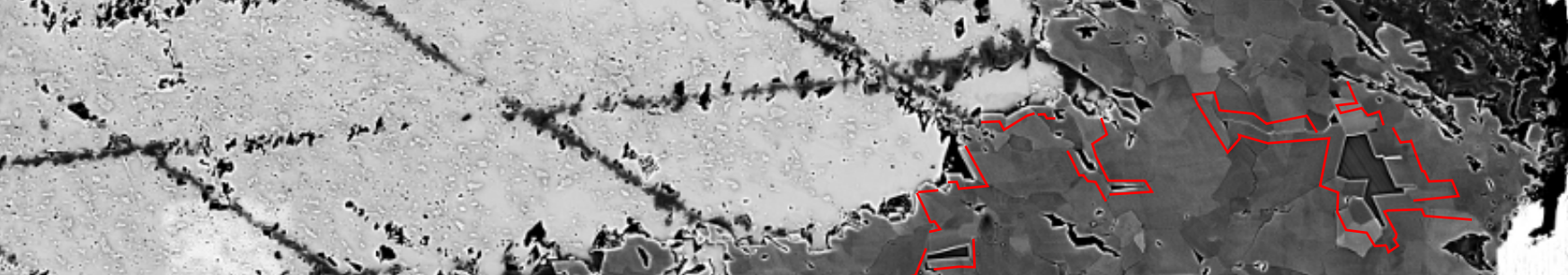

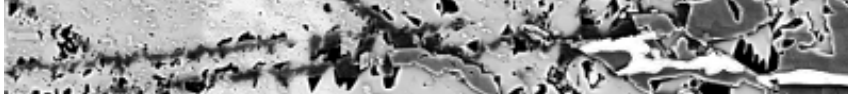

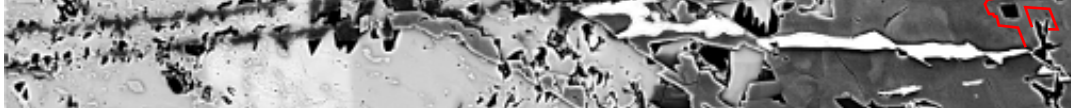

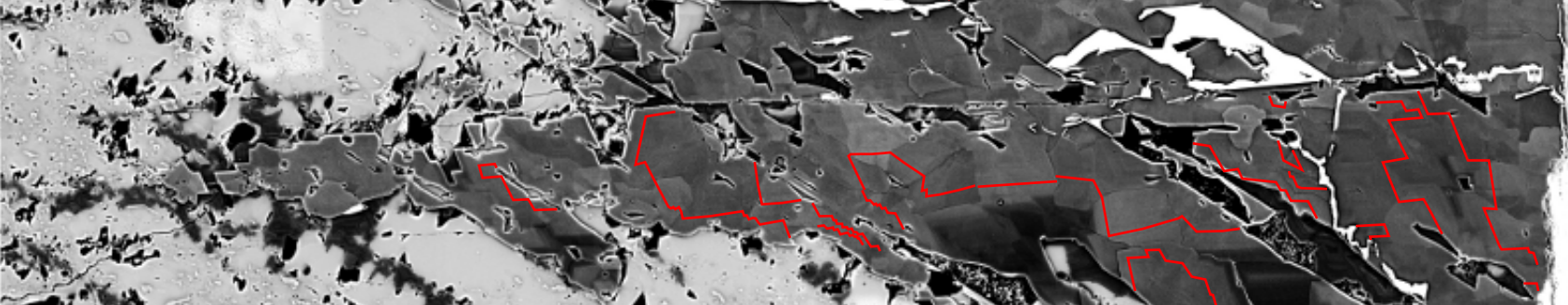

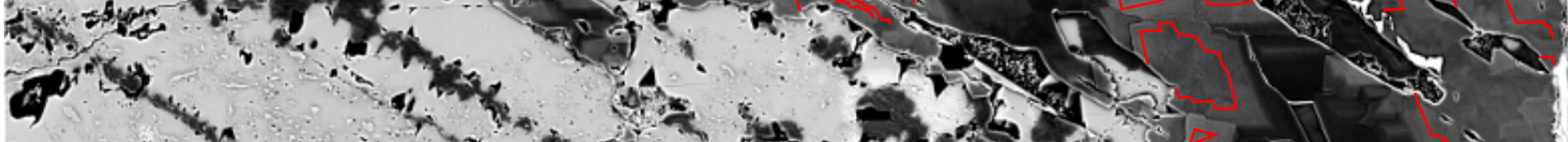

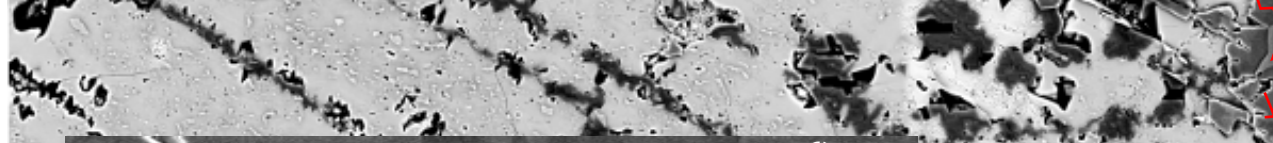

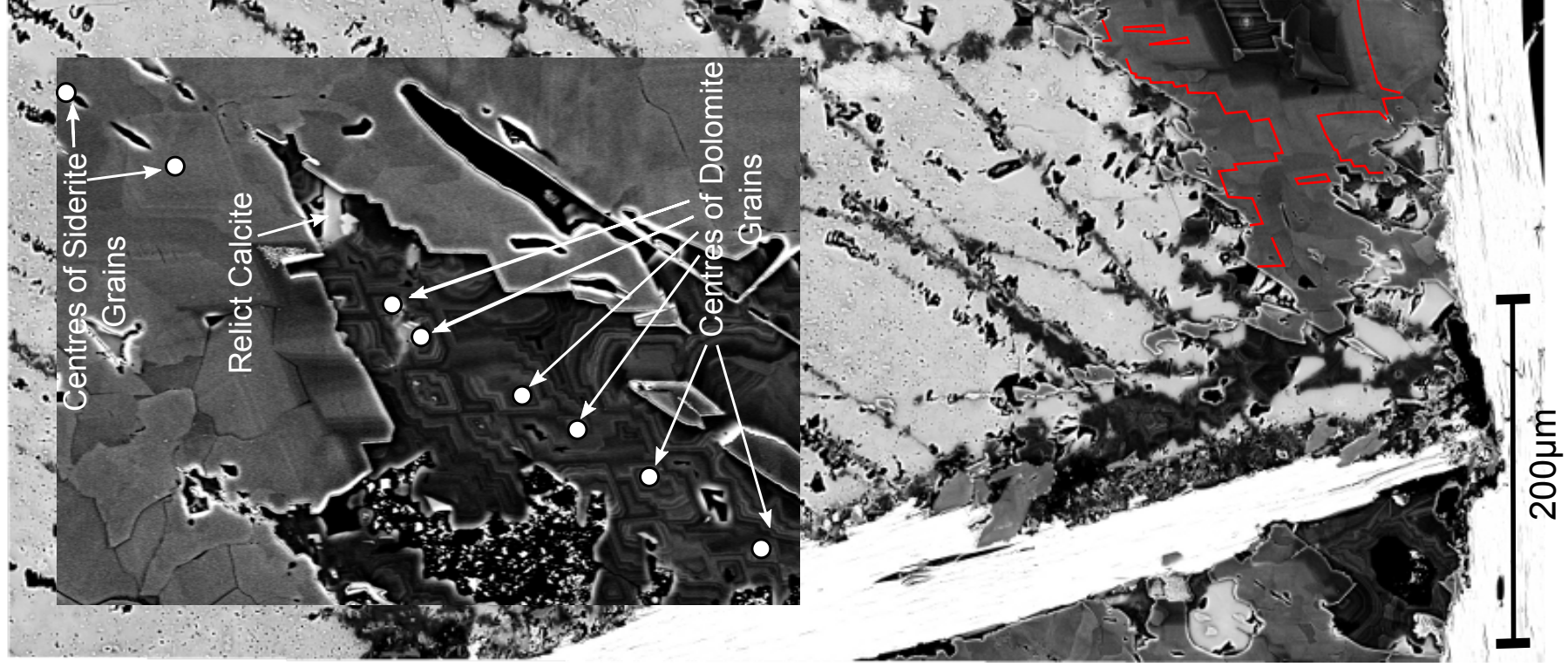




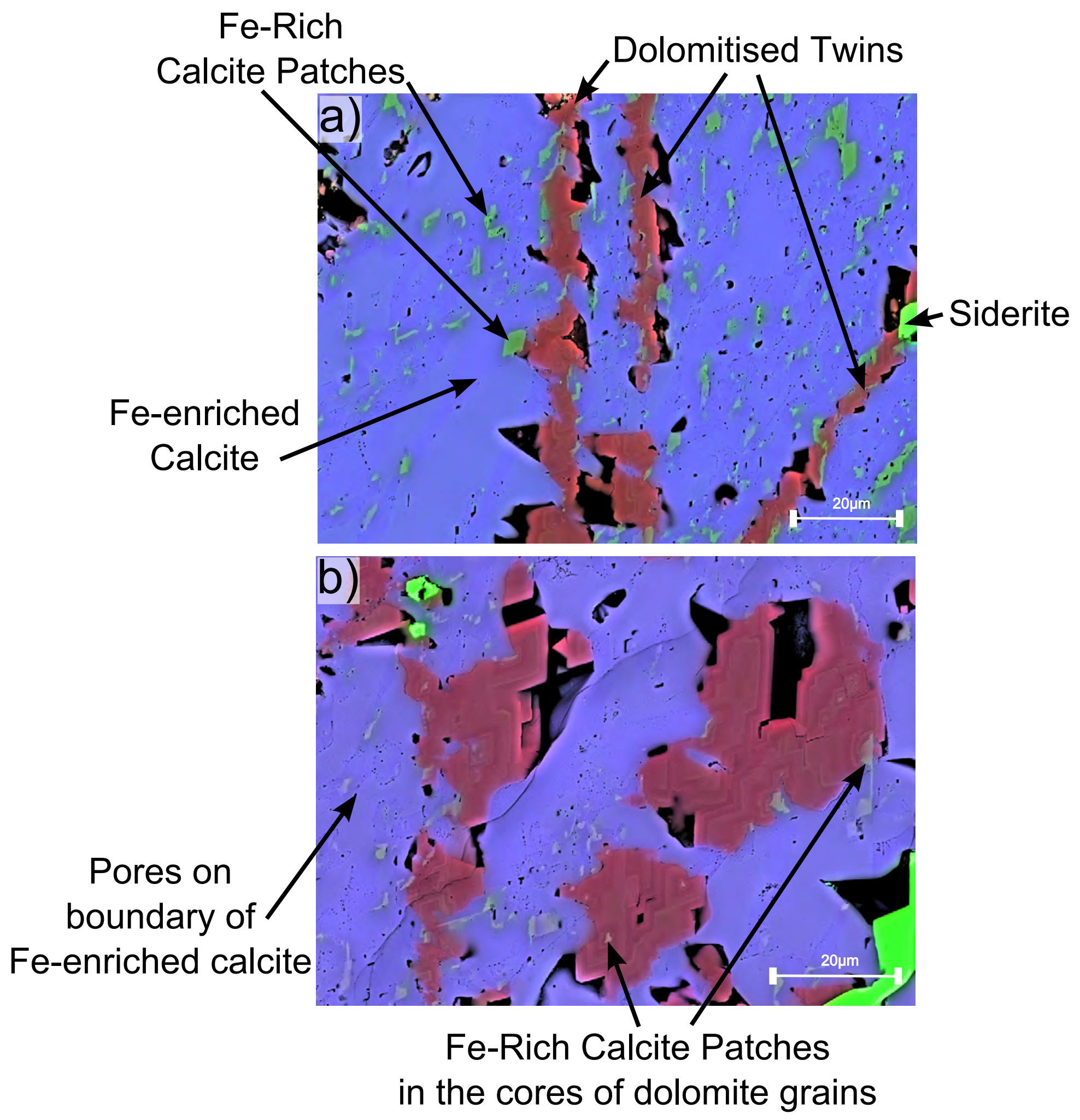



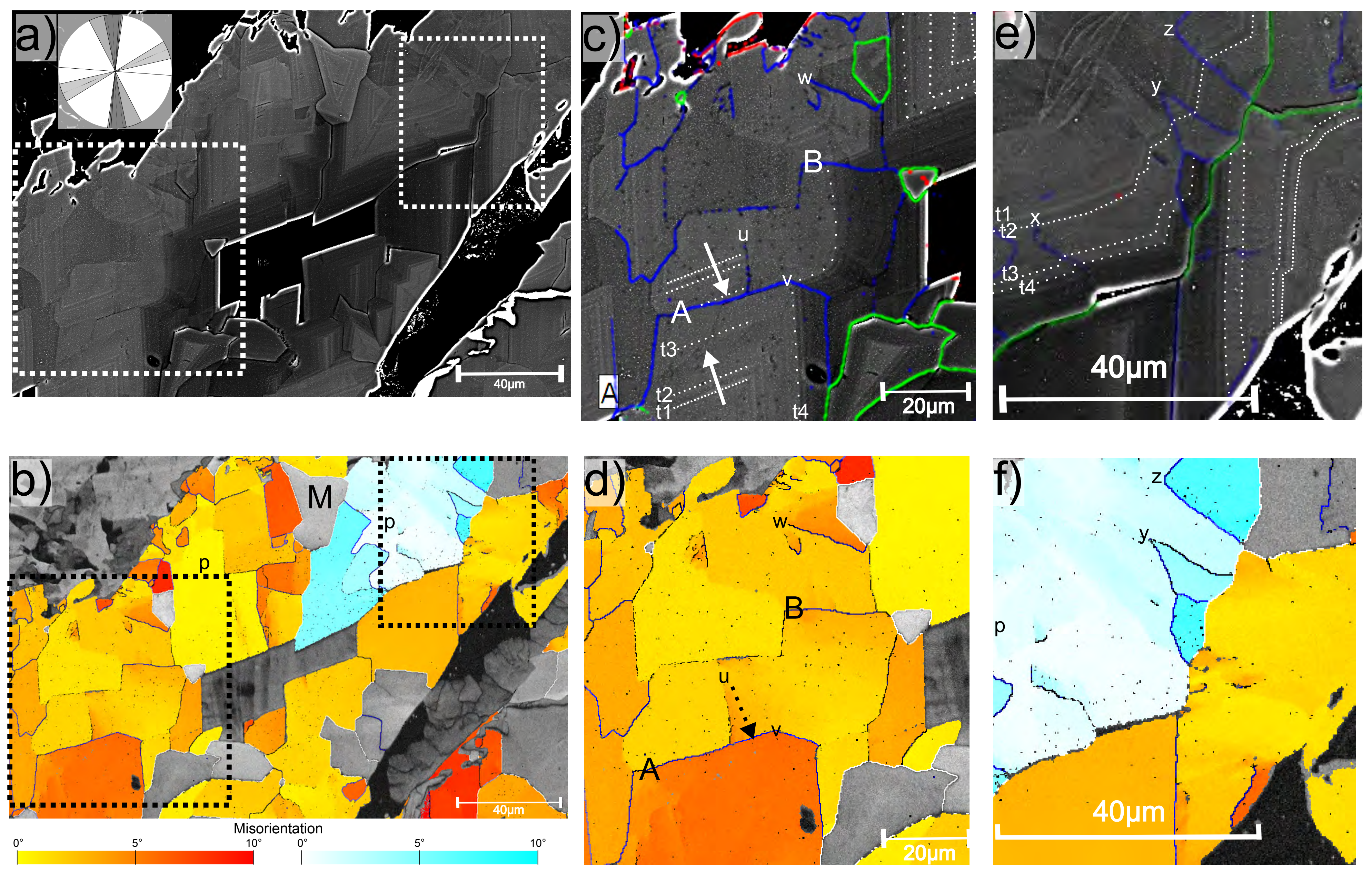


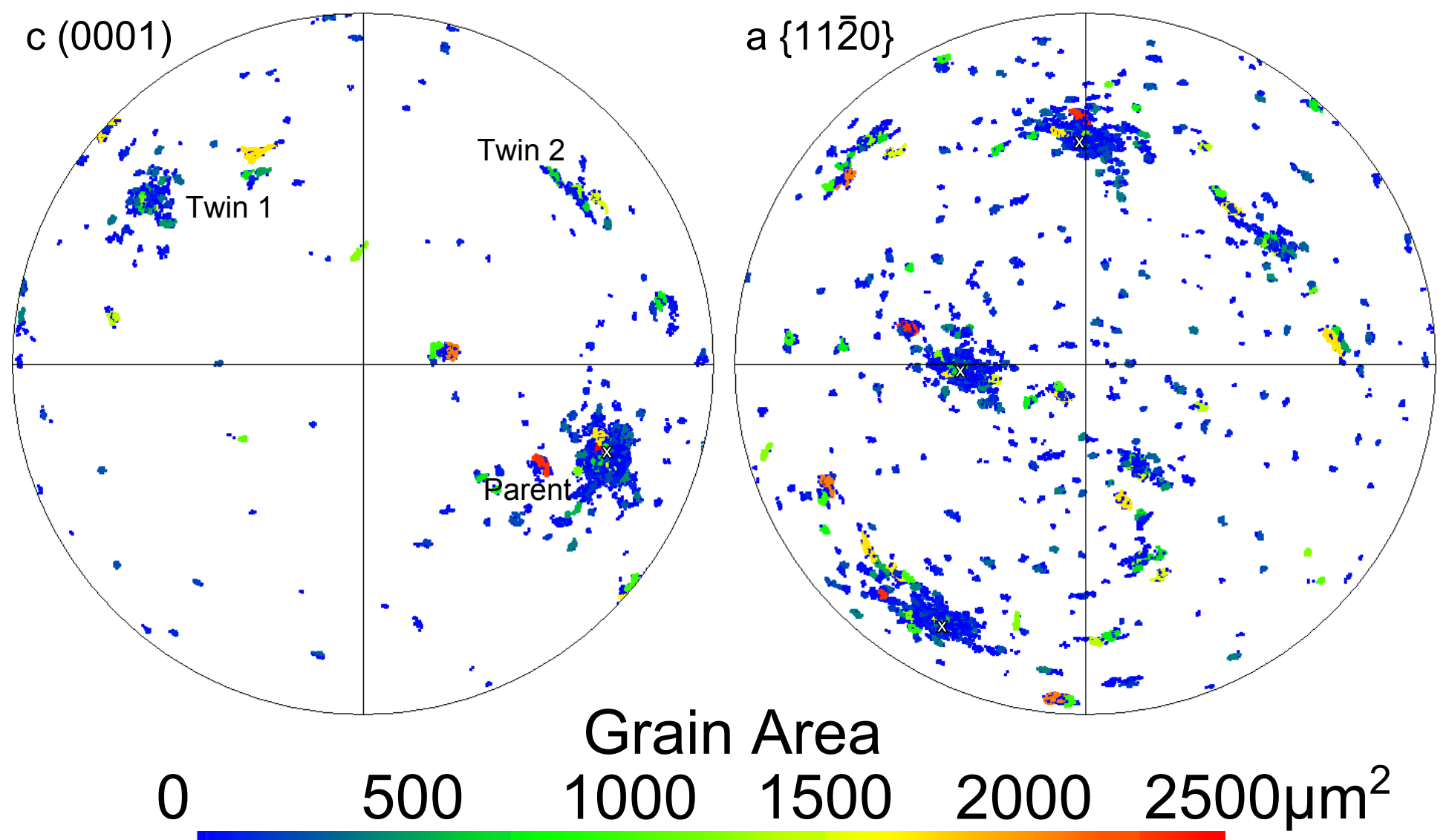


a)

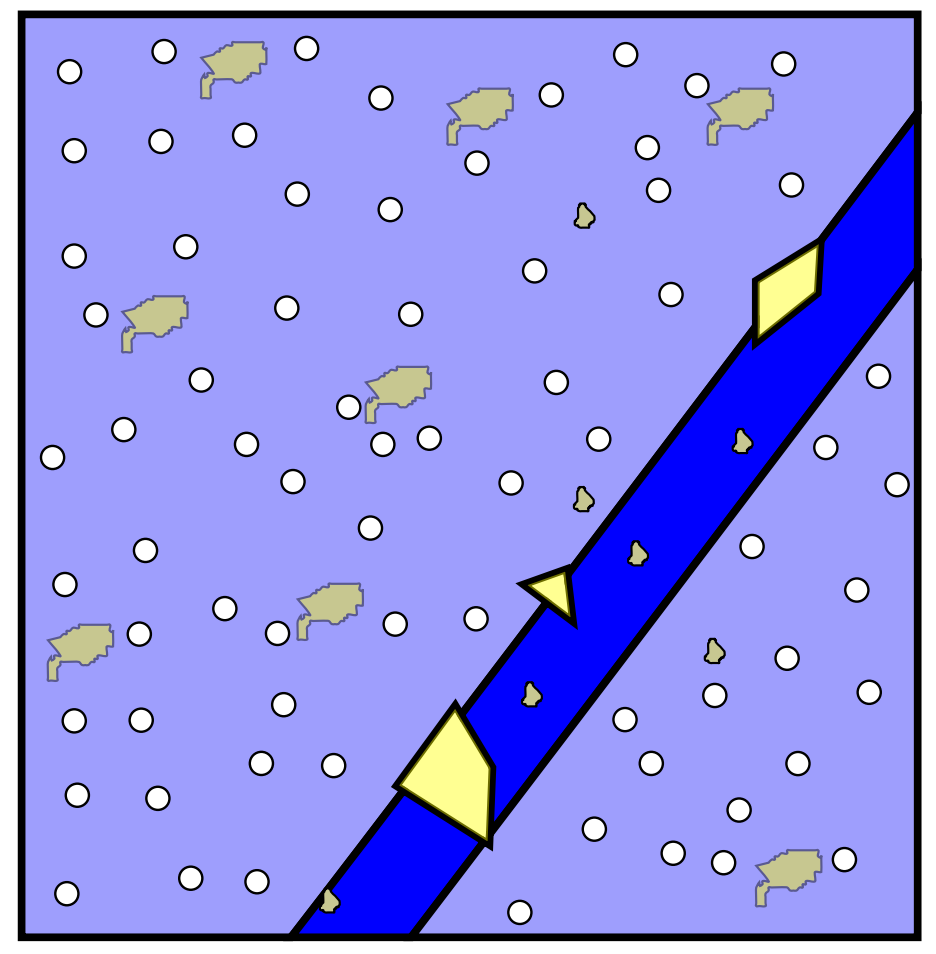

c)

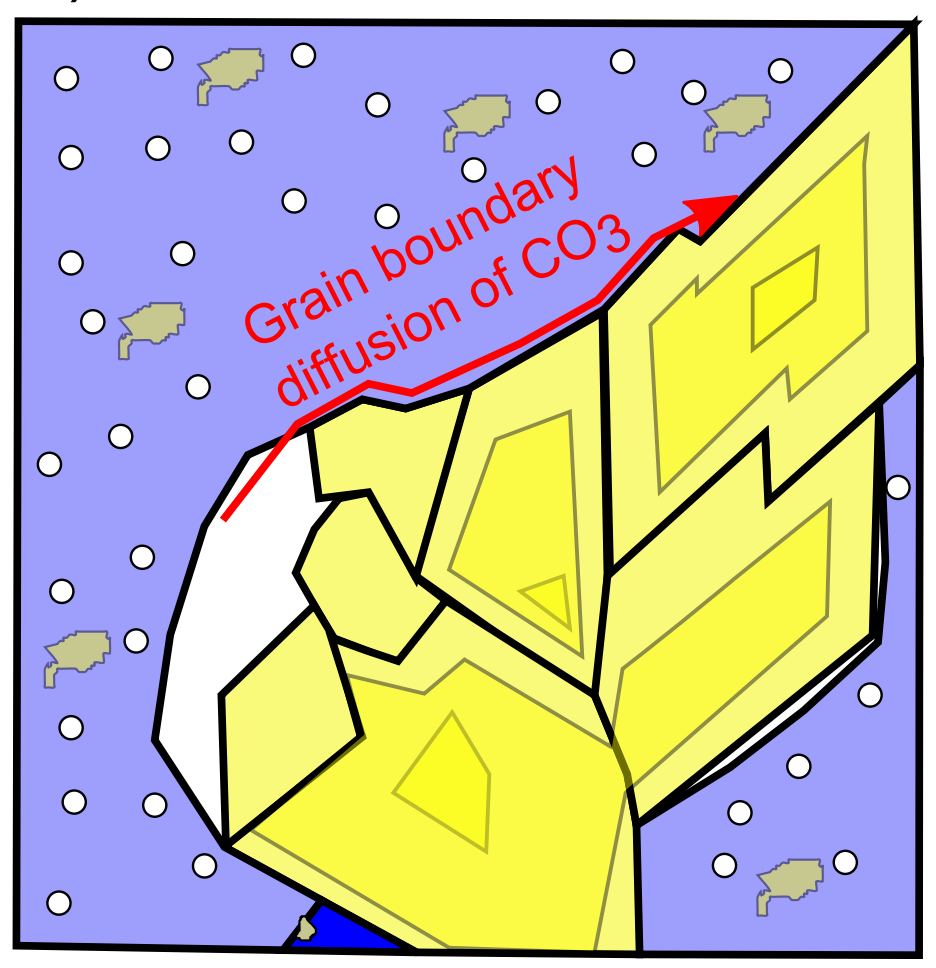

b)

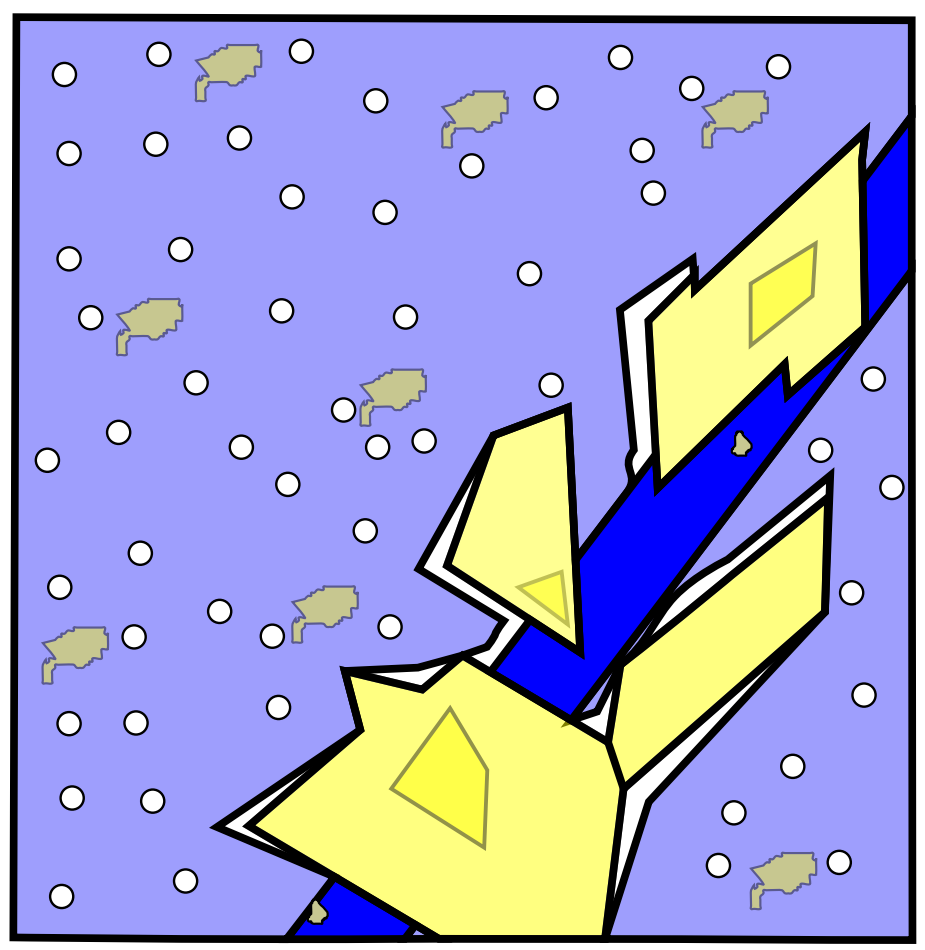

d)

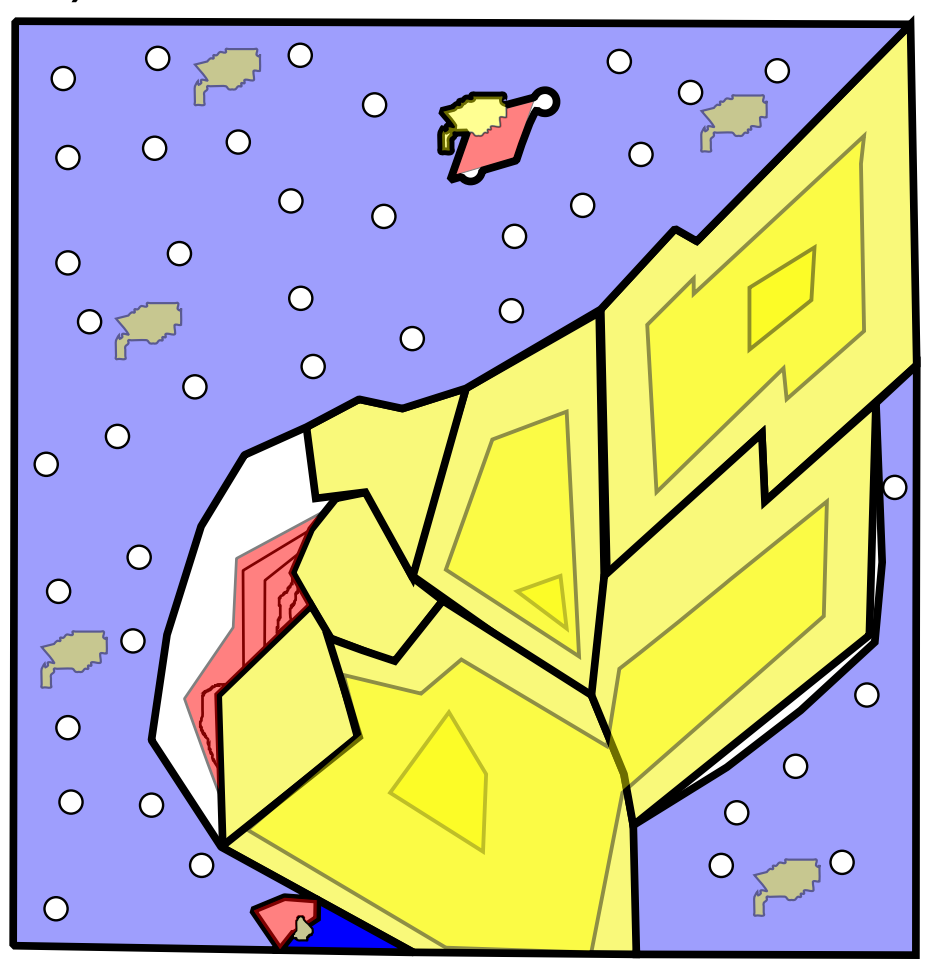

